\title{
Cancelation of Deglacial Thermosteric Sea Level Rise by a Barosteric Effect
}

\author{
GEOFFREY GEBBIE ${ }^{\mathrm{a}}$ \\ ${ }^{a}$ Department of Physical Oceanography, Woods Hole Oceanographic Institution, Woods Hole, Massachusetts
}

(Manuscript received 13 July 2020, in final form 9 October 2020)

\begin{abstract}
Sea level rise over the last deglaciation is dominated by the mass of freshwater added to the oceans by the melting of the great ice sheets. While the steric effect of changing seawater density is secondary over the last 20000 years, processes connected to deglacial warming, the redistribution of salt, and the pressure load of meltwater all influence sea level rise by more than a meter. Here we develop a diagnostic for steric effects that is valid when oceanic mass is changing. This diagnostic accounts for seawater compression due to the added overlying pressure of glacial meltwater, which is here defined to be a barosteric effect. Analysis of three-dimensional global seawater reconstructions of the last deglaciation indicates that thermosteric height change $(1.0-1.5 \mathrm{~m})$ is counteracted by barosteric $(-1.9 \mathrm{~m})$ and halosteric (from -0.4 to $0.0 \mathrm{~m})$ effects. The total deglacial steric effect from -0.7 to $-1.1 \mathrm{~m}$ has the opposite sign of analyses that assume that thermosteric expansion is dominant. Despite the vertical oceanic structure not being well constrained during the Last Glacial Maximum, net seawater contraction appears robust as it occurs in four reconstructions that were produced using different paleoceanographic datasets. Calculations that do not account for changes in ocean pressure give the misleading impression that steric effects enhanced deglacial sea level rise.
\end{abstract}

KEYWORDS: Abyssal circulation; Sea level; Water masses/storage; Climate change; Glaciation; Water budget/balance

\section{Introduction}

Sea level has risen from the Last Glacial Maximum (LGM, about 20000 years ago) to the modern day by $132 \pm 2 \mathrm{~m}$, but the melting of known land and grounded ice during the Last Glacial Maximum is not sufficient $(118 \pm 9 \mathrm{~m})$ to explain the observed sea level rise (at the $5.3 \%$ insignificance level, all errors reported as $1 \sigma$ standard errors; Simms et al. 2019). Determination of the amount of glacial land ice requires investigation of many different ice sheets and had been recently revised (e.g., Carlson et al. 2018; Pico et al. 2018). Part of the discrepancy can be explained by ocean warming, but there are disparate estimates of the sensitivity of global sea level to mean ocean temperature: $13 \mathrm{~cm}^{\circ} \mathrm{C}^{-1}$ in the twentieth century (Bindoff et al. 2007), $17 \mathrm{~cm}^{\circ} \mathrm{C}^{-1}$ for the last interglacial (McKay et al. 2011), or $20-60 \mathrm{~cm}^{\circ} \mathrm{C}^{-1}$ for the equilibrium response (Meehl et al. 2007). For a deglacial mean ocean temperature increase of roughly $2.6^{\circ} \mathrm{C}$ (Bereiter et al. 2018b), oceanic thermal expansion is expected to raise sea level by anywhere from several tens of centimeters up to nearly $2 \mathrm{~m}$. The range is wide in part due to the considered depth range in the sensitivity calculations, where longer time scales and deeper ocean adjustments should lead to larger values. A further uncertainty arises from assuming that steric sea level rise (i.e., those caused by seawater density variations) is dominated by temperature change (e.g., Lowe and Gregory 2006; Griffies and Greatbatch 2012), because the physical processes of the twentieth century may not be a good analog for the last deglaciation. Although none of these factors are likely to explain the entire deglacial sea level discrepancy, they may narrow the difference.

Deglacial sea level rise is clearly dominated by the thickness of added meltwater, but it is also worth reconsidering the

Corresponding author: Geoffrey Gebbie, ggebbie@whoi.edu physical processes that occur under so much ocean freshening. Global-mean sea level rise due to the addition of freshwater has been idealized as having two steps: 1) a rise due to the thickness of freshwater and 2) the mixing of meltwater into the existing ocean (Munk 2003). The addition of meltwater in step 1 changes the mass of the ocean, leading to a barystatic effect on global-mean sea level change (Gregory et al. 2013; Rye et al. 2014). Physical oceanographers have traditionally referred to this as the eustatic effect, but such terminology conflicts with the glaciological convention and is suppressed here. The additional sea level change in step 2 due to mixing, seawater density change, and mass redistribution is smaller, but could still incur a $1-\mathrm{m}$ change for a $1 \%$ effect. While the schematic of Munk (2003) indicates a sea level rise in step 2, the nonlinearity of the equation of state can also give rise to densification and sea level fall due to cabbeling (e.g., Gille 2004; Griffies and Greatbatch 2012). The addition of meltwater also causes an increase in pressure and seawater density due to the slight compressibility of seawater, which is here termed a barosteric effect in analogy with thermosteric and halosteric effects. A question is whether higher-order processes such as the barosteric effect that are safely ignored in the modern problem may become significant over the last deglaciation.

To explicitly account for effects that are neglected in the modern problem, we develop new diagnostics for deglacial steric sea level rise by adapting the modern steric-height definition for this longer time scale (section 2). In particular, the deglacial sea level evolution depends upon details of the thermodynamic equation of state, the hypsometry of the sea floor (e.g., Becker et al. 2009), the changing area of the sea surface, and seawater compressibility. All of these factors are taken into account by comparing three-dimensional oceanic temperature and salinity reconstructions of the Last Glacial Maximum to their modern-day counterpart, where we extend the work of Gebbie et al. (2019) to analyze the physical 
processes of sea level change (section 3). This detailed regional analysis corroborates simple scaling laws for the global ocean derived in section 2. Although the compressibility of seawater may be safely neglected over the modern warming era, a barosteric effect from the increased pressure due to input of glacial meltwater can compensate for most or all of the thermosteric effect (section 4). The discrepancy in deglacial sea level rise and ice loss estimates is more difficult to reconcile if the deglacial ocean contracted (section 5).

\section{Steric sea level change when oceanic mass increases}

Munk (2003) idealized late-twentieth-century sea level rise as a series of two-step processes where mass is added to the ocean and then seawater density is modified through boundary fluxes, mixing, transport, and other processes. Here we apply this idealization to the last deglaciation with knowledge of only the deglacial end states (i.e., the Last Glacial Maximum, $t_{g}=$ $24-18$ kyr before present, and the modern day, $t_{m}=1990 \mathrm{~s}$ ). The accuracy of the two-step approximation is addressed in section 5. Here we identify steric sea level rise as occurring during the second idealized step, and we seek its leading-order contributors for the last deglaciation.

The deglacial end states are denoted $g$ for the LGM and $m$ for the modern day (Fig. 1), and information is available about glacial and modern hydrographic distributions and deglacial sea level rise, $\eta\left(t_{m}\right)-\eta\left(t_{g}\right)$. Here we perform a scaling analysis with the global ocean modeled as a water column where sea level rise is equal to the change in ocean thickness, $H_{m}-H_{g}$, although our detailed analysis will show later that hypsometric effects cannot be ignored for the deglaciation (e.g., Becker et al. 2009). In the first deglacial step, freshwater of thickness $h_{M}$ is added to balance the deglacial mass budget, which includes any mass input by glacial meltwater, changes in atmospheric water vapor, groundwater, or lake levels. Our scaling analysis assumes that salt is conserved due to the long time scale of oceanic salt import and export (e.g., Martin and Whitfield 1983). After freshwater is added, the ocean arrives at an intermediate deglacial state, denoted $i$, that has the same mass as the modern ocean, but its sea level will generally differ from the modern. Here we define this difference as $h_{\rho}$, the steric effect incurred by changing seawater density (i.e., $h_{\rho}=H_{m}-H_{g}-h_{M}$ ) that occurs during the second deglacial step.

Deglacial sea level change is the sum of contributions from the two idealized steps. We define the global-mean sea level change in the first step, $h_{M}=H_{i}-H_{g}$, as the barystatic effect (Gregory et al. 2013) and $M$ refers to oceanic mass. This effect accounts for global-mean sea level rise when ocean mass is increased by adding water, but excludes steric effects. All other contributions to sea level rise occur in the second idealized step and are here considered to be steric: $h_{\rho}=H_{m}-H_{i}$.

Increased oceanic mass leads to increased pressure in the water column and at the sea floor, which causes seawater to become denser due to its slight compressibility. This densification is a steric effect rather than a barystatic effect. To isolate this barosteric effect, we define the intermediate state as having glacial waters with an unchanged thickness as follows the

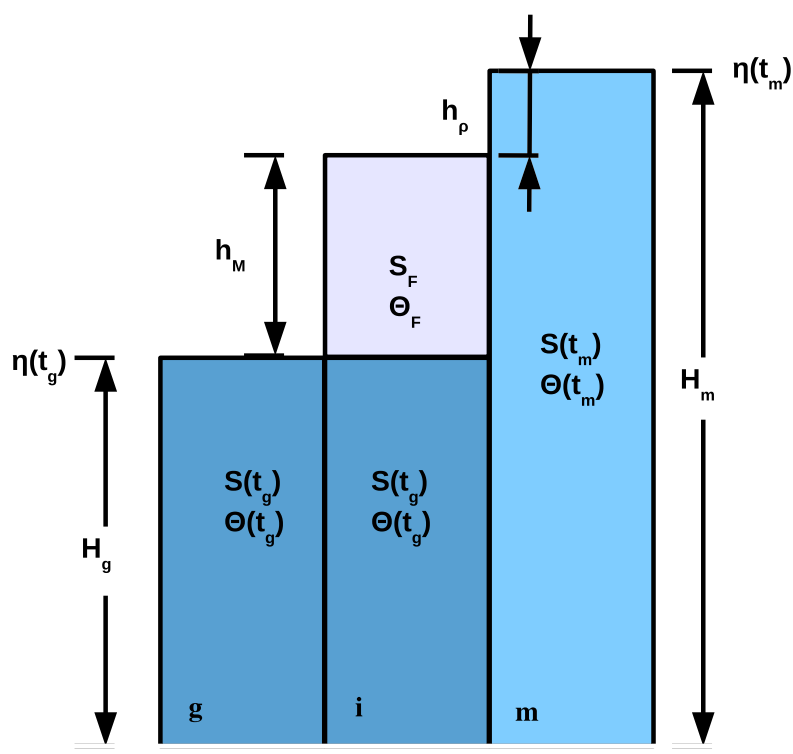

FIG. 1. Schematic of deglacial sea level rise in the case of added freshwater and conserved salt. The glacial state $g$ is described by an ocean thickness of $H_{g}$, sea level of $\eta\left(t_{g}\right)$, salinity of $S\left(t_{g}\right)$, and temperature of $\Theta\left(t_{g}\right)$. The intermediate state includes a freshwater layer with salinity of $S_{F}$ and temperature of $\Theta_{F}$ that has an increased thickness of $h_{M}$ due to the added mass of freshwater. The modern state $m$ has a salinity of $S\left(t_{m}\right)$, temperature of $\Theta\left(t_{m}\right)$, a sea level of $\eta\left(t_{m}\right)$, and a thickness that has changed by the steric effect of changing seawater density $h_{\rho}$.

schematic of Munk (2003). Then the second step of the deglaciation accounts for exchange through boundary fluxes, mixing, and transport in the transition to state $m$. Now the barystatic effect occurs between states $g$ and $i$, while the barosteric effect occurs between states $i$ and $m$.

Analysis of the steric effect involves the comparison of ocean states $i$ and $m$ that have the same mass. These ocean states have the same pressure at the sea floor in accordance with the weight of the overlying mass. Here we define $P_{g}$ to be the pressure on the glacial sea floor and $\Delta P$ to be the additional pressure due to the added deglacial mass. The pressure on the modern sea floor must be the sum of these two contributions (i.e., $P_{m}=P_{g}+\Delta P$ ). Therefore, ocean states $i$ and $m$ are most easily compared in pressure coordinates over the same range of values (Fig. 2). Glacial waters transition to the modern state by changing their temperature and salinity, but also by being subjected to a pressure increase of $\Delta P$. Next we develop a pressure-based diagnostic in order to decompose the temperature, salinity, and pressure contributions to the steric effect on sea level.

Under the simplifying assumption that seawater properties are spatially uniform in the modern and glacial oceans, we scale the contributions to the steric effect. The thickness of the intermediate ocean is the sum of contributions from two layers in Fig. 2,

$$
H_{i} \approx \frac{1}{g}\left(v_{F} \Delta P+v_{g} P_{g}\right)
$$




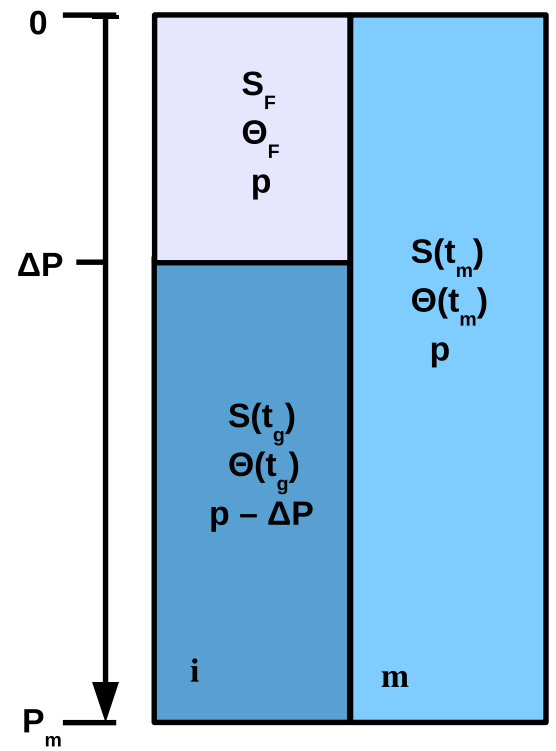

FIG. 2. Pressure-based schematic of deglacial sea level rise due to steric effects in the case that salt is conserved. Waters are categorized as glacial (dark blue), freshwater (gray), and modern (light blue). The depth coordinate is sea pressure from $p=0$ to $p=P_{m}$. Glacial waters of state $i$ have a pressure of $p-\Delta P$ in the schematic, such that the range of pressures, from $p=0$ to $p=P_{m}-\Delta P$, is correct.

where $g$ is gravity, and $v_{F}$ and $v_{g}$ are the specific volumes of freshwater and the LGM ocean, respectively. The modern thickness can be expressed similarly,

$$
H_{m} \approx \frac{1}{g}\left(v_{m} \Delta P+v_{m} P_{g}\right),
$$

where $v_{m}$ is the specific volume of the modern ocean, and we used the relation, $P_{m}=\Delta P+P_{g}$. The difference between (2) and (1) is the steric effect,

$$
h_{\rho} \approx \frac{1}{g}\left[\left(v_{m}-v_{F}\right) \Delta P+\left(v_{m}-v_{g}\right) P_{g}\right]
$$

where the first and second terms on the right hand side are related to density changes in an upper layer with a pressure range $\Delta P$ and a lower layer with pressure range $P_{g}$, respectively. The layer interface corresponds closely to LGM sea level, and we refer to these layers as being above and below LGM sea level for convenience.

The specific volume change below LGM sea level, $v_{m}-v_{g}$, is diagnosed assuming salinity and temperature values of $S_{g}$ and $\Theta_{g}$ for the LGM, and $S_{m}$ and $\Theta_{m}$ for the modern. A linearized equation of state approximates the specific volume changes as, $\Delta v=v_{0}(\alpha \Delta \Theta-\beta \Delta S-\gamma \Delta P)$, where $v_{0}$ is the reference specific volume, $\Delta \Theta, \Delta S$, and $\Delta P$ are the deglacial changes in temperature, salinity, and pressure, respectively, and the three coefficients, $\alpha, \beta$, and $\gamma$, represent the sensitivity of specific volume to these three factors. The conservation of salt requires that $S_{g} P_{g}=S_{m} P_{m}$, and therefore deglacial salinity decreases due to dilution: $\Delta S=-S_{m} \Delta P / P_{g}$. Below LGM sea level, the lower layer expands due to warming and the replacement of salt by freshwater, but contracts due to compressibility,

$$
v_{m}-v_{g} \approx v_{0}\left(\alpha \Delta \Theta+\frac{\beta S_{m} \Delta P}{P_{g}}-\gamma \Delta P\right) .
$$

The specific volume change above LGM sea level, $v_{m}-v_{F}$, requires the comparison of the modern ocean and glacial meltwater. This layer expands due to deglacial warming, but contracts when freshwater is replaced by salt mixed upward from the deep ocean,

$$
v_{m}-v_{F} \approx v_{0}\left(\alpha \Theta_{m}-\beta S_{m}\right),
$$

where it is assumed that glacial meltwater enters the ocean at the freezing point. In other scenarios, the reference temperature for this added water may be nonzero, leading to a thermal expansion of $v_{0} \alpha\left(\Theta_{m}-\Theta_{\text {ref }}\right)$ instead.

Substitution of Eqs. (4) and (5) into (3) yields the total steric effect,

$$
h_{\rho} \approx \frac{v_{0}}{g}\left\{\alpha P_{g} \Delta \Theta+\alpha \Theta_{m} \Delta P-\gamma P_{g} \Delta P\right\},
$$

where the halosteric terms marked by $\beta$ vanish under assumption of globally uniform properties (to be revisited later in section 4c). Substituting the relations, $H_{g}=v_{0} P_{g} / g$ and $\Delta P=$ $g h_{M} / v_{F}$, shows that steric height changes are caused by temperature changes or added mass,

$$
h_{\rho} \approx\left\{\alpha H_{g}\right\} \Delta \Theta+\left\{\alpha \Theta_{m}-\gamma P_{g}\right\} h_{M},
$$

where we accept errors at the $5 \%$ level by assuming that $v_{0} / v_{F} \approx 1$.

Thermosteric height change $h_{\rho \theta}$ is here defined as all contributions in (7) that depend on the thermal expansion coefficient, $\alpha$. The first thermosteric contribution, $\alpha H_{g} \Delta \Theta$, reflects warming in a form that is familiar from modern studies. The second contribution, $\alpha \Theta_{m} h_{M}$, is not considered in modern studies, and represents expansion by warming of glacial meltwater. For the deglaciation, the ratio of the first to second thermosteric terms, $\left(H_{g} / h_{M}\right) \times$ $\left(\Delta \Theta / \Theta_{m}\right)$, is roughly 5 , where we used $\Delta \Theta=3^{\circ} \mathrm{C}$ (Bereiter et al. 2018b) and $\Theta_{m}=15^{\circ} \mathrm{C}$ for the upper ocean. Thus, the new thermosteric term may be a $20 \%$ modification to the total effect.

The term with isentropic compressibility, $\gamma$, on the righthand size of (7) is due to compression by the excess pressure of freshwater loading. This process has a small influence in the twentieth century and is not mentioned or named in a recent review paper (Gregory et al. 2019). This steric effect is driven by pressure, not temperature, and is here called the barosteric effect $h_{\rho p}$ in analogy with the thermosteric effect. The ratio of the largest thermosteric term to the barosteric term is $-\alpha \Delta \Theta / \gamma \Delta P$, as is most easily seen in Eq. (6). Although $\gamma$ appears exceedingly small, the thermosteric-to-barosteric ratio is about -1 for the deglaciation $\left[-10^{-4}{ }^{\circ} \mathrm{C}^{-1} \times 3^{\circ} \mathrm{C} /\left(4 \times 10^{-6} \mathrm{dbar}^{-1}\right) / 10^{2} \mathrm{dbar} \approx-1\right]$. The thermal expansion coefficient varies strongly with temperature and salinity, and here we have chosen a value of $\alpha$ that best represents global-mean effects (detailed later in section $4 \mathrm{a}$ ). The deglacial barosteric effect, $-\gamma P_{g} h_{M}$ in Eq. (7), approaches $-2 \mathrm{~m}$ [i.e., a sea level fall, $-\left(4 \times 10^{-6} \mathrm{dbar}^{-1}\right) \times$ $\left.\left(4 \times 10^{3} \mathrm{dbar}\right) \times 10^{2} \mathrm{~m} \approx-1.6 \mathrm{~m}\right]$. It is not clear whether 
thermosteric expansion or barosteric contraction of seawater wins out over the last deglaciation.

When regional and depth variations in ocean properties are taken into account, does the barosteric effect remain large enough to compensate for deglacial thermosteric expansion? An accurate regional analysis also needs to account for the redistribution of salt and nonlinearities in the equation of state. This motivates an analysis of deglacial steric height that accounts for all of these factors with adequate spatial resolution. Next we test whether our expectations for global-mean thermosteric and barosteric effects hold true when globally integrating over many water columns with disparate characteristics.

\section{Water column analysis method}

\section{a. Deglacial scenarios}

Deglacial changes in seawater density and freshwater content are inferred from global, three-dimensional temperature and salinity reconstructions for the LGM. In particular, we use four scenarios of LGM temperature and salinity derived by combining ocean circulation models with paleoceanographic observations: G12 (Gebbie 2012), G14 and G14A (Gebbie 2014), and GPLS2 (Gebbie et al. 2015). The scenarios are not completely independent, as they used various combinations of the data from the MARGO sea surface temperature (Kucera et al. 2006; Waelbroeck et al. 2009), subsurface temperature and salinity derived from pore waters (Adkins et al. 2002) and $\mathrm{Mg} / \mathrm{Ca}$ (Skinner and Shackleton 2005), and benthic foraminiferal $\delta^{18} \mathrm{O}, \delta^{13} \mathrm{C}$, and $\mathrm{Cd} / \mathrm{Ca}$ (Hesse et al. 2011; Peterson et al. 2014). Other recent three-dimensional reconstructions of glacial temperature and salinity are available (e.g., KurahashiNakamura et al. 2017; Amrhein et al. 2018; Breitkreuz et al. 2019), but these products are not as useful here because they estimate mean oceanic temperature changes of less than $1.5^{\circ} \mathrm{C}$ (Breitkreuz et al. 2019) that are far outside the constraints given by noble gasses trapped in ice cores (Bereiter et al. 2018a). The four reconstructions used here are summarized more completely by Gebbie et al. (2019).

All four reconstructions are gridded with $4^{\circ} \times 4^{\circ}$ horizontal resolution and 33 vertical levels, giving a total of 2806 water columns. For all water columns, it is assumed that the glacial sea level is $130 \mathrm{~m}$ lower than modern day as is consistent with recent observations of the global mean (Austermann et al. 2013; Lambeck et al. 2014; Nakada et al. 2016; Simms et al. 2019). The assumed uniform sea level rise does not account for changes in ocean circulation (e.g., Stammer et al. 2013), changes in the solid Earth (e.g., Mitrovica and Peltier 1991), or gravitational attraction of the ice and ocean (e.g., Gomez et al. 2010).

The thermodynamic equation of state (IOC, SCOR, and IAPSO 2010) is used to compute seawater density change and the oceanic freshwater budget over the deglaciation. The hydrostatic pressure equations are discretized to solve for the pressure at the base of the 33 levels of the gridded reconstructions, and the local gravitational constant is taken as a function of latitude. Glacial scenarios are compared against the modern-day climatology for the time of the World Ocean Circulation Experiment $\left(t_{m}=1990-2002\right.$; Gouretski and Koltermann 2004).

\section{b. Accounting for salt redistribution}

This work aims to corroborate the scaling analysis of section 2 by performing a column-by-column steric height analysis. Then the results are integrated over the global ocean to determine the steric effect on global-mean sea level. Individual water columns exchange salt with the surrounding ocean or the sea floor during the flooding of the continental shelves, and therefore it is not valid to assume that salt is conserved on a column-by-column basis. Where the modern ocean depth is greater than $130 \mathrm{~m}$, the sea level height difference, $\Delta \eta=\eta\left(t_{m}\right)-\eta\left(t_{g}\right)$, is equivalent to the added thickness of seawater over the deglaciation, $H_{m}-H_{g}$, as long as there is no vertical land movement. Where the modern ocean is shallower than $130 \mathrm{~m}$, however, modern sea level is defined but glacial sea level is not. Therefore, we proceed to develop equations for the change in ocean thickness that are applicable in both cases, and then they are related to sea level rise.

The redistribution of both salt and freshwater is considered by integrating the hydrostatic pressure equation for each water column according to appendix A. Deglacial changes in seafloor hydrostatic pressure are divided into contributions $\Delta P_{F}$ and $\Delta P_{S}$ from freshwater and salt, respectively. These contributions are proportional to the thickness of added freshwater, $h_{M F}=v_{F} \Delta P_{F} / g$, and salt, $h_{M S}=v_{S} \Delta P_{S} / g$, where the specific volume of sea salt is $v_{S}=1 /\left(2170 \mathrm{~kg} \mathrm{~m}^{-3}\right)$ (e.g., Tada and Siever 1986). The deglacial thickness change has two contributions (i.e., $h_{M}=h_{M F}+h_{M S}$ ), as shown in the updated schematic where deglacial salt is added (left panel, Fig. 3). The steric height change can be inferred from the mass budgets, where $h_{\rho}=H_{m}-H_{g}-h_{M F}-h_{M S}$. The quantity $H_{m}-H_{g}$ is assumed known from absolute sea level constraints and the seafloor bathymetry, and $h_{M F}$ and $h_{M S}$ are computed from the oceanic mass budget.

The previous equations hold when salt is removed from a water column despite $\Delta P_{S}$ and $h_{M S}$ being negative. In particular, the steric height change $h_{\rho}$ is still determined by the difference between the $H_{m}$ and $H_{i}$. It is difficult to schematically illustrate a negative mass, however, so the mass budget is rearranged to obtain: $H_{g}+h_{M F}=H_{m}-h_{M S}$, where $-h_{M S}$ is now a positive value. Thus, the combined thickness of the glacial ocean and added freshwater is equal to that of the modern ocean and removed salt (right panel, Fig. 3).

\section{c. Steric effect when salt is not conserved}

We update the pressure-based comparison of ocean states $i$ and $m$ to account for salt import and export so that the steric height change can be decomposed into physical contributions. Diagnostics of the $3 \mathrm{D}$ ocean reconstructions proceed with vertical integrals over the entire water column, as detailed in appendix B. For illustrative purposes, we proceed here as if the ocean properties are homogeneous over the various layers of interest.

The thickness of ocean state $i$ has contributions from three layers,

$$
H_{i}=\frac{1}{g}\left\{v_{S} \Delta P_{S}+v_{F} \Delta P_{F}+v_{g} P_{g}\right\},
$$


(a)

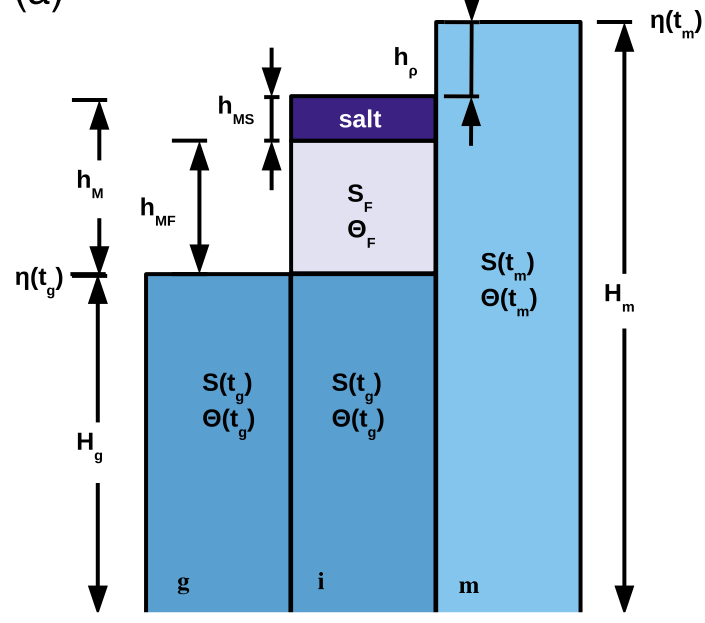

(b)

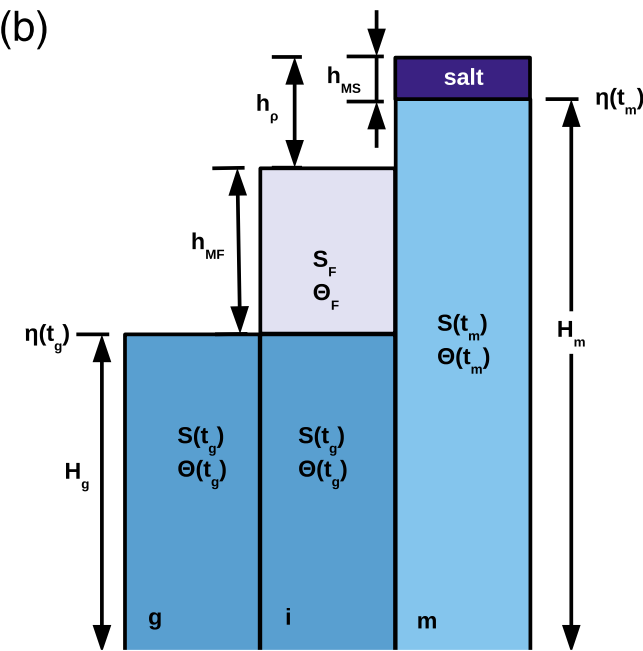

FIG. 3. Schematic of deglacial thickness change in the case of (left) added freshwater and salt and (right) added freshwater and removed salt.

where the terms in the curly brackets include the thickness of added salt, the added freshwater, and the glacial water column, respectively. Vertical integrals are approximated by assuming homogeneous ocean properties in each layer. Modern oceanic thickness can also be decomposed into three terms:

$$
H_{m}=\frac{1}{g}\left\{v_{m} \Delta P_{S}+v_{m} \Delta P_{F}+v_{m} P_{g}\right\},
$$

and the steric height change is the difference of (9) and (8),

$$
h_{\rho}=\frac{1}{g}\left[\left(v_{m}-v_{S}\right) \Delta P_{S}+\left(v_{m}-v_{F}\right) \Delta P_{F}+\left(v_{m}-v_{g}\right) P_{g}\right],
$$

in analogy with Eq. (3). When salt is added and $\Delta P_{S}>0$, then the steric height change is interpreted as the sum of contributions from three layers defined by their pressure ranges (left panel, Fig. 4).

When salt is removed, it is not straightforward to interpret the first term in curly brackets of Eq. (10) because $\Delta P_{S}$ involves a negative pressure interval. Substituting the relation $\Delta P_{F}=\Delta P-\Delta P_{S}$ and rearranging (10), we obtain,

$h_{\rho}=\frac{1}{g}\left\{\left(v_{S}-v_{F}\right)\left(-\Delta P_{S}\right)+\left(v_{m}-v_{F}\right) \Delta P+\left(v_{m}-v_{g}\right) P_{g}\right\}$,

where $\left(-\Delta P_{S}\right)$ is a positive value and we can again relate these terms to contributions from three pressure layers. This transformation permits the specific volume of ocean states $i$ and $m$ to be compared consistently with a vertical pressure coordinate (right panel, Fig. 4).

\section{d. Decomposition of steric contributions}

Salinity increases when salt is added and decreases when freshwater is added,

$$
\Delta S=\frac{1-S_{m}}{P_{g}} \Delta P_{S}-\frac{S_{m}}{P_{g}} \Delta P_{F},
$$

where we use $\Delta P_{S}=P_{m} S_{m}-P_{g} S_{g}$ and $\Delta P=\Delta P_{S}+\Delta P_{F}$. We substitute a linearized equation of state and Eq. (12) into Eq. (10) to find,

$$
h_{\rho} \approx\left\{\alpha H_{g}\right\} \Delta \Theta+\left\{\alpha \Theta_{m}-\gamma P_{g}\right\} h_{M F}+\left\{\frac{v_{0}-v_{S}}{v_{S}}-\frac{\beta v_{0}}{v_{S}}\right\} h_{M S},
$$

where terms on the order of $10^{-3} h_{\mathrm{MF}}$ are neglected. Thus, Eq. (7) is modified to include a new term involving $h_{M S}$ that is dominated by the redistribution of salt among water columns.

The addition of salt to a water column causes the competition of multiple processes of physical chemistry (e.g., Pilson 1998). The ratio, $\left(v_{0}-v_{S}\right) / v_{S} \approx 1.1$, is related to expansion by the phase change of salt from solid to dissolved forms.
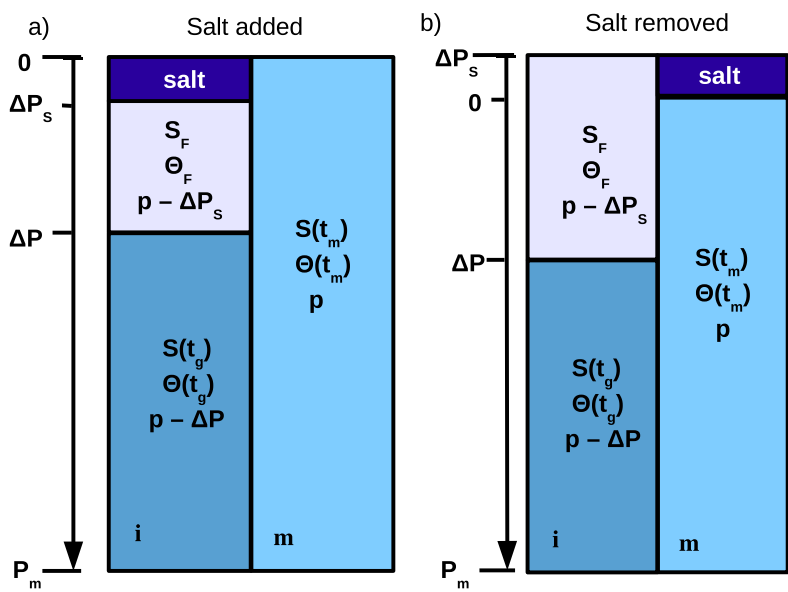

FIG. 4. Pressure-coordinate schematic for diagnosing steric height change when (a) salt is added and (b) salt is removed. 


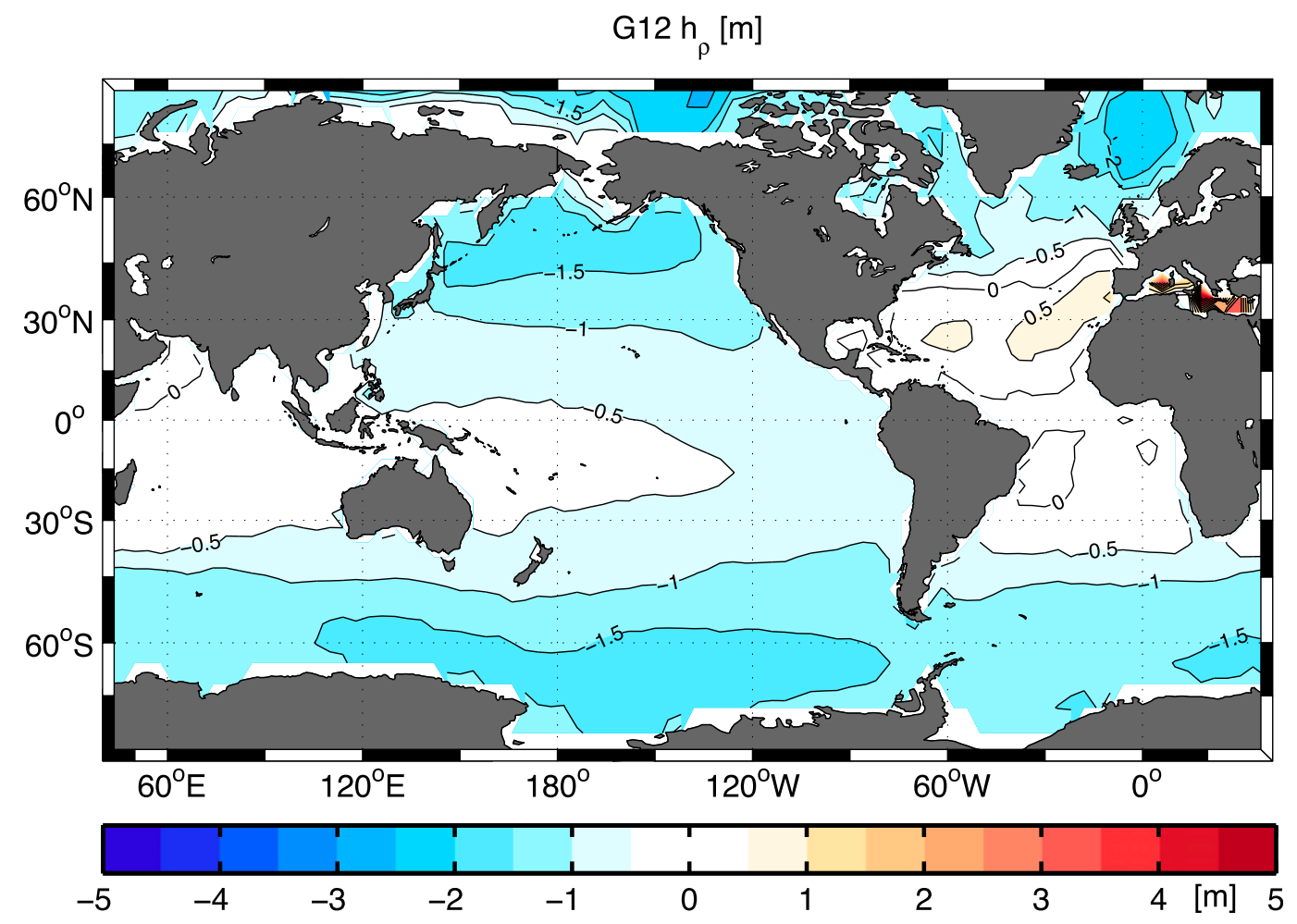

FIG. 5. Deglacial steric height change $h_{\rho}$ due to all seawater density variations in scenario G12.

This expansion is always accompanied by a contraction due to salt ions being accommodated in the molecular structure of water, however, and contraction wins out $\left(-\beta v_{0} / v_{S} \approx-1.5\right)$. Both the expansion and contraction could be considered halosteric in nature, but here we keep the expansion separate and label it the phase-change effect $h_{\rho \phi}$, as it is not directly related to $\beta$ in the linearized equation of state. The contraction term is here defined as the halosteric height change $h_{\rho s}$. When salt is added to a column, the sum of $h_{M S}, h_{\rho \phi}$, and $h_{\rho s}$ indicates a sea level rise of about $60 \%$ of the thickness of added salt, as can be confirmed in a simple kitchen experiment.

The thermosteric and barosteric terms from Eq. (7) remain in (13), but $h_{M}$ is modified to $h_{M F}$. Local $h_{M S}$ values are as large as $\pm 2 \mathrm{~m}$ due to internal salt redistribution (appendix A), giving rise to halosteric height change $h_{\rho s}$ that is $50 \%$ larger in magnitude and a phase-change effect $h_{\rho \phi}$ that is about $10 \%$ larger. Therefore these steric contributions related to salt are locally comparable in size to the thermosteric and barosteric effects.

The local steric height change is the sum of thermosteric, barosteric, halosteric, and phase-change effects: $h_{\rho}=h_{\rho \theta}+h_{\rho p}+$ $h_{\rho s}+h_{\rho \phi}$. Deglacial steric height change is well described by these four contributions in the three-dimensional analysis of LGM and modern ocean properties (appendix B). The difference between $h_{\rho}$ calculated by the mass budget versus the seawater density change has a mean and standard deviation of -3 and $2 \mathrm{~mm}$, respectively. Thus, no nonlinear terms appear to be necessary at this high level of accuracy. The steric effect on global-mean deglacial sea level rise is given by an area-weighted average,

$$
\overline{h_{\rho}}=\frac{\sum_{i=1}^{N_{x}} \sum_{j=1}^{N_{y}} h_{\rho}(i, j) A(i, j)}{\sum_{i=1}^{N_{x}} \sum_{j=1}^{N_{y}} A(i, j)},
$$

where $N_{x}=90$ and $N_{y}=45$ in the reconstructions used in this work, $A(i, j)$ is the area of a surface grid face, and $A_{m}=\sum_{i=1}^{N_{x}} \sum_{j=1}^{N_{y}} A(i, j)$ is the modern-day oceanic surface area. Through this final step, the detailed water-column diagnostics can be directly compared to the global-mean scaling in section 2 .

\section{Spatial estimates of deglacial steric effects}

The deglacial steric height change for 2806 water columns is diagnosed through the mass budget and confirmed through the analysis of seawater density change. Both calculations indicate that most locations have negative $h_{\rho}$ values reflecting a contraction of seawater over the last deglaciation (Fig. 5). Contraction is largest in the polar regions, with more than $2.0 \mathrm{~m}$ of steric height fall in the Arctic and $1.5 \mathrm{~m}$ in the Southern Ocean. The global-mean steric height change is inferred by taking the areaweighted global average of $h_{\rho}$, and we find a steric height change between -0.7 and $-1.1 \mathrm{~m}$ in the four scenarios (Table 1 ), despite their lack of consensus regarding water-mass characteristics and hydrographic structure (Gebbie et al. 2019).

The negative $\overline{h_{\rho}}$ value requires the schematics of Figs. 1 and 3 to be revised. The addition of a meltwater lid makes the 
TABLE 1. Deglacial, global-mean sea level rise (m) due to oceanic mass change (or the barystatic effect), freshwater mass change, salt mass change, steric effect, halosteric effect, thermosteric effect, barosteric effect, and phase-change effect (columns 2-9, respectively), as calculated using four LGM reconstructions (listed in column 1): G12, G14, G14A, and GPLS2.

\begin{tabular}{ccccccrr}
\hline \hline LGM scenario & $\overline{h_{M}}$ & $\overline{h_{M F}}$ & $\overline{h_{M S}}$ & $\overline{h_{\rho}}$ & $\overline{h_{\rho s}}$ & $\overline{h_{\rho \theta}}$ & $\overline{h_{\rho p}}$ \\
\hline G12 & 124.99 & 124.87 & 0.12 & -0.66 & -0.33 & 1.49 & -1.93 \\
G14 & 125.22 & 125.07 & 0.16 & -0.89 & -0.40 & 1.27 & -1.93 \\
G14A & 125.45 & 125.36 & 0.10 & -1.12 & -0.31 & 1.02 & -1.93 \\
GPLS2 & 125.35 & 125.44 & -0.09 & -1.02 & -0.02 & 1.04 & -1.92 \\
\hline
\end{tabular}

intermediate-state ocean stand higher, not lower, than the modern day. Of course, the intermediate state should not be interpreted as a high sea level stand during the deglaciation, but instead that steric height change compensated for $0.7-1.1 \mathrm{~m}$ of the deglacial sea level rise. Equivalently, the thickness of deglacial meltwater is greater than the assumed sea level rise of $130 \mathrm{~m}$ in most places. Therefore, the discrepancy between estimates of absolute sea level rise and the melting of land ice cannot be explained by the expansion of seawater; rather the ocean is undergoing a net contraction during the deglaciation that requires additional meltwater, not less, to balance the sea level budget.

\section{a. Thermosteric effect}

The four LGM scenarios do not give a consistent picture of where deglacial warming occurs, as there are cases with polar-amplified warming (G14A), low-latitude warming (G12, GPLS2), and uniform warming (G14). Despite the lack of agreement, the thermosteric effect leads to expansion that is enhanced in the subtropics and tropics in all cases. Scenario G12, for example, has an expansion of 1-3 $\mathrm{m}$ in the low latitudes (top panel, Fig. 6). Thermosteric height change is small in the polar regions, not due to a lack of temperature change, but due to the reduced (and sometimes negative) thermal expansion coefficient in cold water (e.g., Gille 2004). The spatial pattern of thermal expansion is similar to those found in modern warming scenarios (e.g., Lowe and Gregory 2006; Piecuch and Ponte 2011), although the modern ocean has smaller expansion rates due to limited deep-ocean participation.

The global-mean thermosteric height change is $1.5 \mathrm{~m}$ in scenario G12 as found by taking the area-weighted average of $h_{\rho \theta}$. The other scenarios give lower values of 1.0-1.3 m that can be explained by their corresponding mean ocean temperature change. In fact, mean ocean temperature change $\Delta \bar{\Theta}$ predicts the thermal expansion with a standard error of less than $5 \mathrm{~mm}$ when using linear relationship: $\overline{h_{\rho \theta}}=\left(46 \mathrm{~cm}^{\circ} \mathrm{C}^{-1}\right) \Delta \bar{\Theta}+9 \mathrm{~cm}$ (Fig. 7). The slope is about 3 times larger than modern estimates (Bindoff et al. 2007; McKay et al. 2011).

The slope of the linear regression is explained by comparison of homogeneous LGM and modern water columns as in section 2. The area-weighted mean of the $\alpha$ terms in Eq. (13) yields the thermosteric sea level change,

$$
\overline{h_{\rho \theta}}=\left\{\alpha H_{g}\right\} \Delta \bar{\Theta}+\left\{\alpha \overline{\Theta_{m}}\right\} h_{M F},
$$

where the two terms represent thermal expansion below and above LGM sea level, respectively. The sensitivity of sea level rise to mean temperature change is then,

$$
\frac{\overline{h_{\rho \theta}}}{\Delta \bar{\Theta}}=\alpha H_{g},
$$

which gives a value of $40 \mathrm{~cm}^{\circ} \mathrm{C}^{-1}$ that is close to the regressed value [i.e., $10^{-4}{ }^{\circ} \mathrm{C}^{-1} \times\left(4 \times 10^{3} \mathrm{~m}\right)$ ]. The small values of sea level sensitivity inferred in modern studies are due to the surface intensification of warming caused by the lack of time for a complete deep ocean response. This interpretation is consistent with decreasing the depth range $H_{g}$ in Eq. (16).

Both the sensitivity of sea level to warming and the spatial pattern of the top panel of Fig. 6 are largely controlled by thermal expansion below LGM sea level [i.e., first term of Eq. (15)]. The second term, reflecting the expansion caused by the heat required to bring glacial meltwater up to modern temperature, is smaller by roughly an order of magnitude [i.e., $\left.h_{M F} \overline{\Theta_{m}} / H_{g} \Delta \overline{\Theta_{m}} \approx 10^{2} \mathrm{~m} \times 15^{\circ} \mathrm{C} /\left(4 \times 10^{3} \mathrm{~m}\right) / 3^{\circ} \mathrm{C} \approx 10^{-1}\right]$. The thermal expansion of glacial meltwater explains the small but nonzero $y$ intercept of $9 \mathrm{~cm}$ in the regression above $\left[\alpha \overline{\Theta_{m}} h_{M F} \approx\right.$ $\left.\left(4 \times 10^{-5}{ }^{\circ} \mathrm{C}^{-1}\right) \times 15^{\circ} \mathrm{C} \times\left(1.3 \times 10^{2} \mathrm{~m}\right) \approx 8 \times 10^{-2} \mathrm{~m}\right]$, where we have been careful to linearize the equation of state about the average of freshwater and modern seawater which yields a decreased thermal expansion coefficient. Despite the enormous heat storage in the upper $130 \mathrm{~m}$ of the ocean, the reduced thermal expansion coefficient in freshwater limits the impact on sea level.

Our scenarios were not constrained with the deglacial mean ocean temperature change of $2.57^{\circ} \pm 0.24^{\circ} \mathrm{C}$ inferred from noble gasses in an Antarctic ice core (Bereiter et al. 2018b). Using our regression equation with its uncertainties, the noblegas mean ocean temperature change suggests a thermosteric height change of $1.27 \pm 0.09 \mathrm{~m}$ in the center of the range of our four scenarios. As deglacial thermosteric height change is certainly positive, another compensating effect must exist to make the total steric height change negative.

\section{b. Barosteric effect}

The biggest opposing factor to thermal expansion is compression due to the pressure load of meltwater. This contraction is generally larger than the thermal expansion, with a barosteric height change of $-2.5 \mathrm{~m}$ in regions where the ocean is deeper than $4 \mathrm{~km}$ (lower panel, Fig. 6). The barosteric height change in Eq. (13) is

$$
h_{\rho p}=-\left\{\gamma P_{g}\right\} h_{M F},
$$

where contraction is proportional to the water column depth through $P_{g}$. Smaller amounts of contraction are seen along midocean ridges and continental shelves. Over $99.7 \%$ of the spatial 

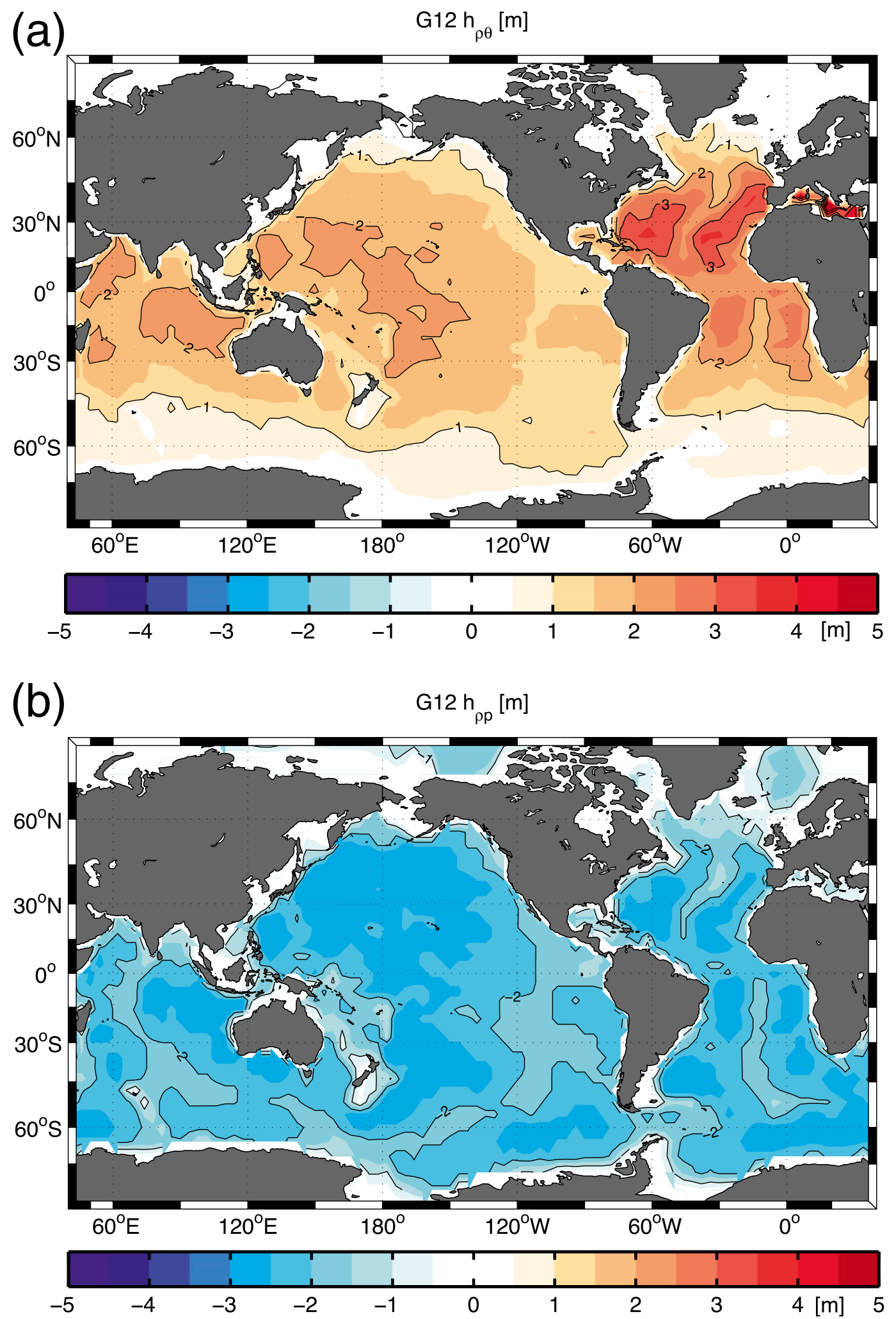

FIG. 6. (top) Thermosteric height change $h_{\rho \theta}$ and (bottom) baro-steric height change $h_{\rho p}$ from scenario G12. 


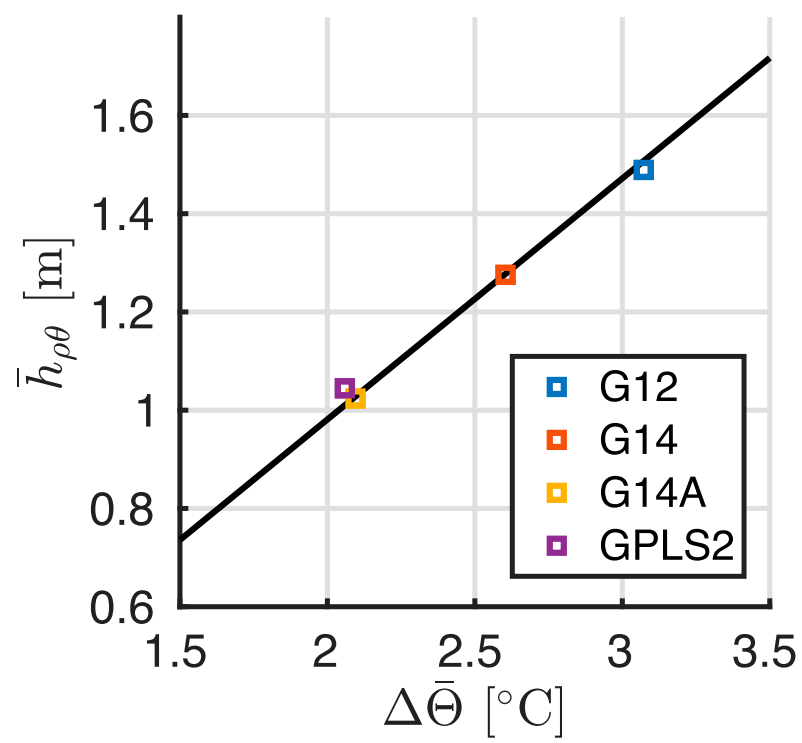

FIG. 7. Global-mean thermosteric effect $\overline{h_{\rho \theta}}$ as a function of the modern-minus-LGM difference in global-mean temperature $\Delta \bar{\Theta}$ in four scenarios, G12, G14, G14A, and GPLS2 (open symbols). The regression fit is given by the solid line.

variance in $h_{\rho p}$ is related to $P_{g}$. A water column that is subjected to a pressure loading at the surface is denser at all depths, and therefore deep water columns cause a greater sea level fall than shallow water columns. Seawater compressibility is slight, but meters of sea level fall occur when the freshwater input is over $100 \mathrm{~m}$.

The global-mean barosteric height change is consistently $\overline{h_{\rho p}}=-1.9 \mathrm{~m}$ in all four scenarios. Thus, the scaling of section 2 correctly suggests that the barosteric effect is the same order of magnitude as the thermosteric effect and it has the opposite sign, as here corroborated in the case that regional variations are taken into account. While barosteric effects appear to explain the deglacial steric-height decrease, an analysis for regional variations must first account for halosteric terms that may be large due to the redistribution of salt before making such a conclusion.

\section{c. Halosteric effect}

The interior (i.e., below LGM sea level) ocean is diluted by meltwater, leading to freshening and seawater expansion, but the effect is compensated by the contraction of the meltwater as it becomes saltier. The compensation is not perfect on a column-bycolumn basis, as the interior expands $2-7 \mathrm{~m}$ (bottom right, Fig. 8 ) and the meltwater lid (i.e., above LGM sea level) contracts 3-3.5 $\mathrm{m}$ (top right, Fig. 8). The sum of these two effects is the total halosteric effect $h_{\rho s}$, which has a spatial distribution with values as large as $\pm 3 \mathrm{~m}$ (top left, Fig. 8). Antarctic Bottom Water was especially salty during the LGM but is relatively fresh today (appendix C). This deglacial freshening incurred an expansion of the water column and positive $h_{\rho s}$ values in locations such as the Weddell Sea. The sign of the effect is reversed in North Atlantic Deep Water, where freshening was smaller than the global average, and reflects an internal redistribution of salt.

Water columns from all four reconstructions are used to evaluate the dependence of $h_{\rho s}$ on added freshwater and salt.
The relation, $h_{\rho s}=-\left(1.3 \times 10^{-3}\right) h_{M F}-1.54 h_{M S}$, fits over $99 \%$ of the variability in $h_{\rho s}$ with a standard error of $4 \mathrm{~cm}$ (gray dots, Fig. 9). More than $99 \%$ of regional variability in $h_{\rho s}$ is due to a redistribution of salt as evident in the $h_{M S}$ spatial pattern (see Fig. A1). Previously, section 3d showed that the scaling, $h_{\rho s}=-\left(v_{0} \beta / v_{S}\right) h_{M S}$, suggests a coefficient of -1.5 that closely approximates the regressed value.

When the salt budget is balanced, previous analyses (e.g., Lowe and Gregory 2006; Gregory et al. 2019) and section 3d suggested that the halosteric effect is nearly vanishing, but here we find a nonzero regression coefficient for $h_{M F}$. A halosteric height change of about $-20 \mathrm{~cm}$ is expected when $130 \mathrm{~m}$ of freshwater are added and salt is conserved $\left[\left(-1.3 \times 10^{-3}\right) \times\right.$ $\left.\left(1.3 \times 10^{2} \mathrm{~m}\right)=-1.7 \times 10^{-1} \mathrm{~m}\right]$, which is consistent with the nonzero $y$ intercept in Fig. 9. This halosteric effect is about twice as large as anticipated from the error analysis of Gregory et al. (2019).

To explain the nonvanishing halosteric effect, we must retain higher-order terms that were neglected in Eq. (13). In particular, those equations assumed a global value for $\beta$ and $v_{0}$, and the next-order terms depend upon the linearized equation of state. Average deglacial values above LGM sea level, $\beta_{\text {lid }}$ and $v_{\text {lid }}$, and below LGM sea level, $\beta_{\text {int }}$ and $v_{\text {int }}$, are not the same (i.e., $\beta_{\text {lid }}=7.8 \times 10^{-1} \mathrm{~kg} \mathrm{~kg}^{-1}, v_{\text {lid }}=9.8 \times 10^{-4} \mathrm{~m}^{3} \mathrm{~kg}^{-1}$, $\beta_{\text {int }}=7.5 \times 10^{-1} \mathrm{~kg} \mathrm{~kg}^{-1}$, and $\left.v_{\text {int }}=9.6 \times 10^{-4} \mathrm{~m}^{3} \mathrm{~kg}^{-1}\right)$. We take into account this subtlety of the equation of state and amend the halosteric height change to be

$$
h_{\rho s} \approx-\left\{\frac{\left(v_{\text {lid }} \beta_{\text {lid }}-v_{\text {int }} \beta_{\text {int }}\right) S_{m}}{v_{F}}\right\} h_{M F}-\left\{\frac{v_{0} \beta}{v_{S}}\right\} h_{M S},
$$

where the correlation of $\beta$ and $v$ with depth renders the previously assumed cancelation of the first term to be no longer perfect (i.e., $v_{\text {lid }} \beta_{\text {lid }}-v_{\text {int }} \beta_{\text {int }}=4 \times 10^{-5} \mathrm{~m}^{3} \mathrm{~kg}^{-1}$ ). By this scaling, the $h_{M F}$ coefficient in (18) is expected to be $-1.4 \times$ $10^{-3}\left[\left(-4 \times 10^{-5} \mathrm{~m}^{3} \mathrm{~kg}^{-1}\right) \times\left(3.5 \times 10^{-2} \mathrm{~kg} \mathrm{~kg}^{-1}\right) /\left(10^{-3} \mathrm{~kg}^{-1} \mathrm{~m}^{3}\right)\right]$, in close accordance with the numerical results. The depth dependence of the equation of state produces a halosteric effect that is systematically negative when freshwater is added and salt is conserved.

The halosteric effect on global-mean sea level $\overline{h_{\rho s}}$ is well approximated by Eq. (18) when global-mean values are substituted. The halosteric height change is estimated to be $-33,-40,-31$, and $-2 \mathrm{~cm}$ in scenarios G12, G14, G14A, and GPLS2, respectively (colored squares, Fig. 9). Small deviations from global salt balance exist in these scenarios, here estimated to be $0.2 \%, 0.3 \%, 0.2 \%$, and $-0.1 \%$ change, respectively. These values indicate a seawater contraction that is proportional to the gain of salt. While the reconstructions are not trusted to resolve these differences, it is possible that the flooding of continental shelves and groundwater processes could export or import these small amounts of salt.

Steric height change due to the phase change of salt, $h_{\rho \phi}$, is needed to maintain mass conservation when considering a water column that has a changing salt inventory. Equation (13) indicates that the phase-change effect is proportional to the amount of added salt,

$$
h_{\rho \phi}=\left(\frac{v_{0}-v_{S}}{v_{S}}\right) h_{M S}
$$


(a)

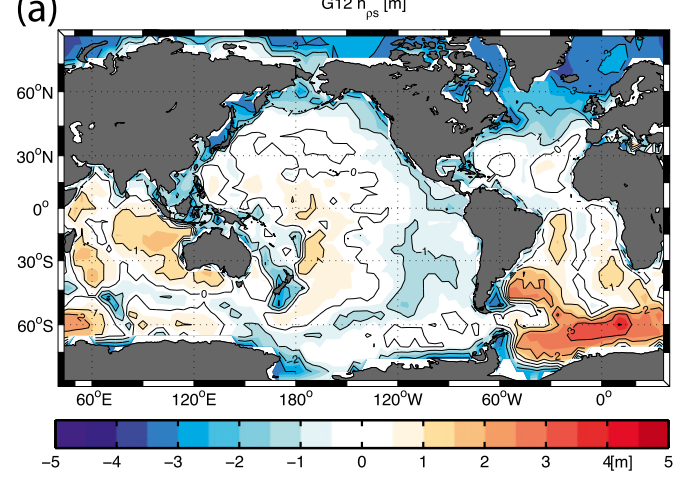

(c)

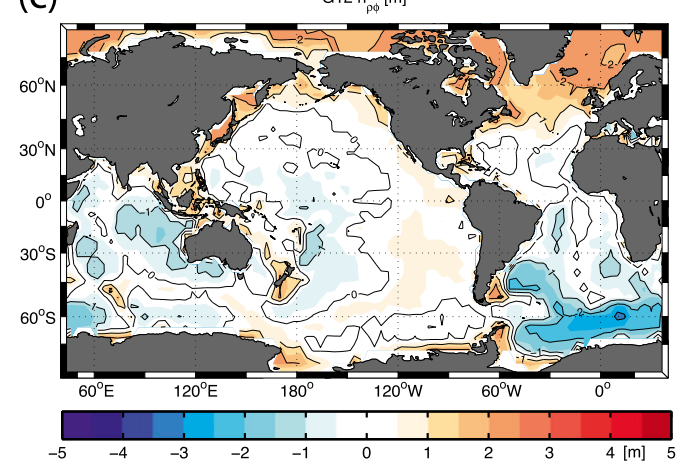

(b)

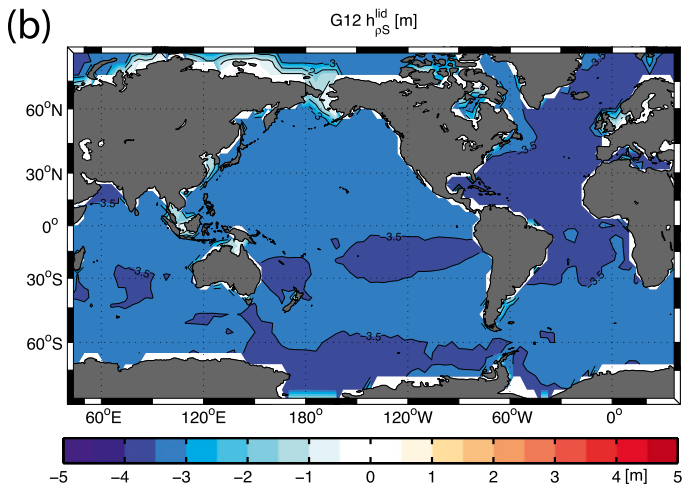

(d)

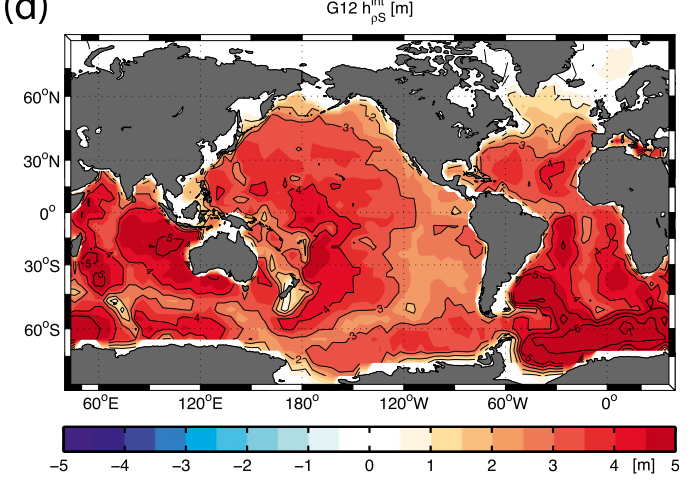

FIG. 8. (a) Halosteric height change $h_{\rho s}$ and (c) height change due to the phase change of salt $h_{\rho \phi}$. The halosteric contribution is decomposed into two parts: (b) the integrated effect $h_{\rho s}^{\text {lid }}$ from the upper ocean where $p<\Delta P$, and (d) $h_{\rho s}^{\text {int }}$ from the interior ocean where $p>\Delta P$. The range of values and basic spatial pattern are consistent among the four reconstructions analyzed here.

where $h_{M S}$ is dominated by internal oceanic redistribution. The net increase in the salt budget is taken into account by the $h_{\rho \phi}$ values, and its pattern is similar to $h_{\rho s}$ but with the opposite sign (Fig. 8, top and bottom left panels). Knowledge of $h_{M S}$ permits an excellent prediction of the phase-change effect, where the regression coefficient is 1.11 for $h_{M S}>0$ and 1.17 for $h_{M S}<0$, as is consistent with the assumption of $v_{0}=1 /\left(1028 \mathrm{~kg} \mathrm{~m}^{-3}\right)$ for salt addition and $v_{0}=1 /\left(1000 \mathrm{~kg} \mathrm{~m}^{-3}\right)$ for salt removal. Both regressions have a $y$ intercept indistinguishable from zero.

The regional redistribution of salt has a smaller effect on deglacial global-mean sea level rise than the thermosteric or barosteric effects. The global-mean average of halosteric and phase-change effects leads to a steric height decrease between 14 and $24 \mathrm{~cm}$ (Table 1 ). Thus, the detailed accounting of regional salt redistribution reinforces the barosteric effect in counteracting deglacial thermal expansion.

\section{Discussion}

\section{a. Assessing the idealized description of the deglaciation}

The barosteric effect on global-mean sea level could be redefined to account for the fact that pressure variations are transmitted more rapidly than the mixing of salinity and temperature. Here we consider an idealized deglaciation where freshwater is added and the accompanying pressure loading is immediately felt throughout the water column. Following Eqs.
(4) and (5), the specific volume change by this pressure increase of $\Delta P$ is,

$$
\Delta v=-v_{0} \gamma \Delta P
$$

where we assume that the ocean is homogeneous and salt is conserved. The barosteric effect would then be defined as,

$$
h_{\rho p}=-\gamma P_{m} h_{M}
$$

This equation has been translated into a form appropriate for diagnosing the three-dimensional ocean reconstructions, and we find that $\overline{h_{\rho p}}=-194 \mathrm{~cm}$ for $\mathrm{G} 12$, as opposed to the value of $-193 \mathrm{~cm}$ found previously. Thus, there is little sensitivity to the order that the barosteric effect is calculated, with a mean offset of $1.0 \mathrm{~cm}$ and a standard deviation of $0.5 \mathrm{~cm}$ among the four scenarios. Temperature and salinity effects are similarly unaffected by the order of operations, as diagnostics of $\overline{h_{\rho}}$ are nearly identical when calculated by the mass budget or by integrating steric effects. In future work, it should be checked that steric height calculated from the endpoints of the deglaciation are consistent with those that temporally resolve the deglacial evolution.

\section{b. Relation to glaciological estimates of sea level rise}

Glaciologists find it convenient to translate the volume of melted land ice into an equivalent sea level rise. Sea level 


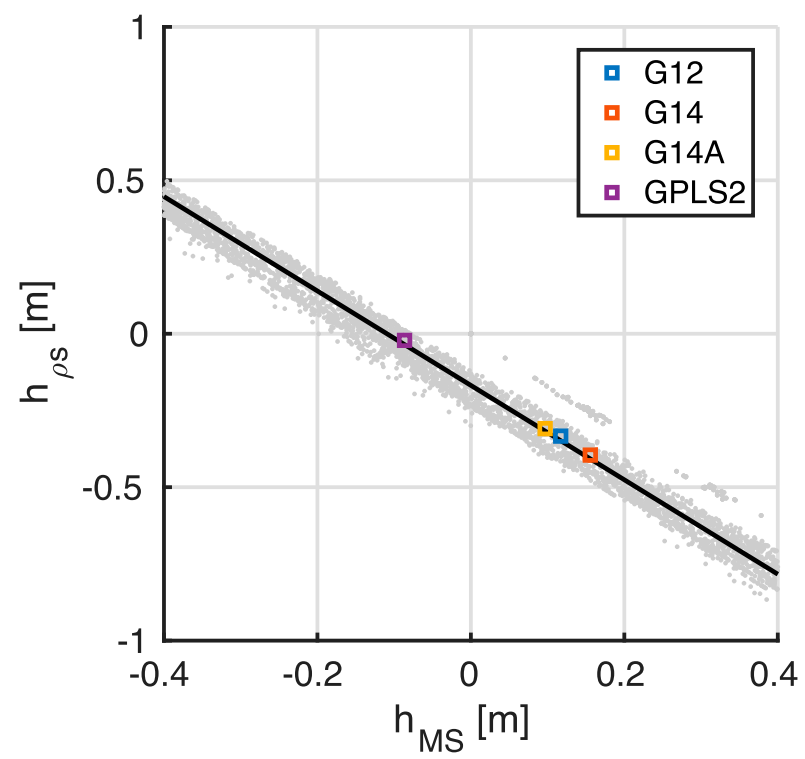

FIG. 9. Scatterplot of $h_{\rho s}$ and $h_{M S}$. Cases are given for the globalmean values from four scenarios (colored squares) and for the individual water columns from all four reconstructions (gray dots). The regression line in the text is given by the black line.

rises by the sum of $h_{M F}, h_{\rho p}$, and $h_{\rho s}$ when freshwater is added and no heating occurs. Following Eq. (13), we find a sea level rise of

$$
h_{M F}+h_{\rho p}+h_{\rho s} \approx\left\{1-\gamma P_{g}-\frac{\left(v_{\text {lid }} \beta_{\text {lid }}-v_{\text {int }} \beta_{\text {int }}\right) S_{m}}{v_{F}}\right\} h_{M F} \text {, }
$$

where terms involving $h_{M S}$ are eliminated and the vertical correlation of $\beta$ and $v$ is included. To first order, the sea level rises by the height of the added freshwater column as indicated by the " 1 " factor in the curly brackets. Recall from section 2 that the barosteric effect provides a coefficient of $-1.6 \times 10^{-2}$. The halosteric effect by the depth dependence in the equation of state was shown in section $4 \mathrm{c}$ to have a coefficient of $-1.4 \times 10^{-3}$. The sum of all coefficients is 0.983 , or that the water rises by $98.3 \mathrm{~cm}$ for every $1 \mathrm{~m}$ of added freshwater. Thus, the steric effect is a sea level drop of approximately $1.7 \mathrm{~cm} \mathrm{~m}^{-1}$. The analysis of Gregory et al. (2019) indicated that sea level would rise by greater than $99.9 \mathrm{~cm}$ for one meter of added freshwater, but their calculation only considered halosteric effects and not the larger effect of seawater compression.

The mass of land ice loss is often translated into an equivalent sea level rise by dividing by the oceanic area and a reference seawater density $\rho_{0}$ that is typically taken to be about $1026 \mathrm{~kg} \mathrm{~m}^{-3}$ (e.g., Lambeck and Chappell 2001; Maris et al. 2014; Patton et al. 2016). By this formula, the equivalent sea level rise for one meter of added freshwater is $97.4 \mathrm{~cm}$ (i.e., $h_{M F} \rho_{F} / \rho_{0}$ ), or about $1 \%$ too low. This discrepancy may partially explain the low bias in LGM ice estimates (Gebbie et al. 2019). The surprising reference density value of about $\rho_{0}=1017 \mathrm{~kg} \mathrm{~m}^{-3}$ gives the sea level equivalent value that most closely matches the true sea level rise of $98.3 \mathrm{~cm}$. Even though a seawater density of $1017 \mathrm{~kg} \mathrm{~m}^{-3}$ is uncommon, that numerical value parameterizes the compressibility of seawater and is the best choice for a reference density when converting between ice mass and ocean volume.

\section{Conclusions}

Sea level rise since the Last Glacial Maximum has been dominated by the mass input of meltwater from ice sheets, with a smaller contribution by thermal expansion. As modernday studies state that global-mean steric sea level change is purely thermosteric (e.g., Gregory et al. 2019), a seemingly logical conclusion is that changes in seawater density acted to raise sea level over the last deglaciation. Here we revisit the steric effect by analyzing the oceanic temperature and salinity changes in four scenarios of the last deglaciation. Our analysis extends modern-day works to include the effect of changing oceanic surface area and the compression of seawater by meltwater pressure loading. Even though thermal expansion raises sea level by $1.0-1.5 \mathrm{~m}$, the contraction of seawater by the additional pressure of $130 \mathrm{~m}$ of meltwater acts to depress sea level by a greater amount: $-1.9 \mathrm{~m}$. Salinity-related effects that are vanishingly small in the modern-day case also contribute to a sea level fall of an additional $0.1-0.3 \mathrm{~m}$. Despite major hydrographic differences between the four deglacial scenarios considered here, net oceanic contraction over the deglaciation is guaranteed for a reasonable range of the mean oceanic temperature change.

As glaciologists have not found enough grounded ice at the Last Glacial Maximum to explain $130 \mathrm{~m}$ of sea level rise, it has been hypothesized that seawater expansion could make up some of the discrepancy. Thermal expansion does help reconcile the discrepancy, but sea level rises by only $0.5 \mathrm{~m}$ for each degree of mean ocean temperature change over the deglaciation. With a best estimate of temperature change of about $2.6^{\circ} \mathrm{C}$ (Bereiter et al. 2018b), thermal expansion can explain $1.3 \mathrm{~m}$, which is small compared to the remaining difference of more than $10 \mathrm{~m}$ (Simms et al. 2019). An additional bias of 1-2 $\mathrm{m}$ comes from the reference seawater density value used to convert ice mass to equivalent sea level rise (Gebbie et al. 2019). The compression of seawater acts against our ability to reconcile glaciological and oceanographic constraints, however. Possible explanations for the remaining discrepancy are that Antarctica was a dumping ground for more glacial ice (Bassett et al. 2007), far-field estimates of sea level rise are more uncertain than previously thought because of the dependence upon just a few locations (e.g., Yokoyama et al. 2001), or that a missing ice sheet existed in a remote location such as eastern Siberia (e.g., Clark and Tarasov 2014).

The impact of compression versus thermal expansion depends upon the ratio of freshwater input to oceanic warming. The ratio is at least 20 times higher for the deglaciation than for the modern warming era. The ratio is set by the thermodynamic energy that goes into melting ice versus ocean heat uptake (e.g., Kuhlbrodt and Gregory 2012), and the ocean-toice heat uptake ratio is estimated to be greater than 30 -to-1 in 
the modern era (e.g., Levitus et al. 2012). Over the deglaciation, the ratio was closer to 1-to-1 (e.g., Galbraith et al. 2016), presumably due to the geometry and response time of the ice sheets (Levermann et al. 2013; Berger et al. 2017). Once the climate system has sufficient time to respond to modern climate change, the ratio of ice melt to ocean warming in the future may become more similar to deglacial values. At that time, sea level processes that are usually neglected, such as the pressure change due to meltwater loading, will become as important as thermal expansion.

Acknowledgments. I thank J. Gregory and S. Griffies for suggesting this work be documented; M. Andres, J. Gregory, and C. Piecuch for reviewing an early manuscript; K. Costa and A. Seltzer for inviting a presentation on this work; L. Lisiecki and A. Simms for introducing me to the problem; I. Fer for serving as the editor; and three anonymous reviewers. GG is supported by NSF OCE-1536380 and OCE-1760878.

Data availability statement. The derived data products associated with the manuscript, including the contributions to deglacial steric height change from four reconstructions, are freely available at the National Centers of Environmental Information under identification noaa-model-31472 (https:// www.ncdc.noaa.gov/paleo/study/31472).

\section{APPENDIX A}

\section{Deglacial Mass Budget}

Glacial and modern distributions of seawater temperature and salinity permit the added deglacial mass of freshwater and salt to be diagnosed through their effects on hydrostatic pressure. The overlying mass of freshwater contributes to a pressure

$$
p_{F}(t, z)=\int_{z}^{\eta(t)}\left[1-S\left(t, z^{\prime}\right)\right] \rho\left(t, z^{\prime}\right) g d z^{\prime}
$$

and the weight of salt contributes

$$
p_{S}(t, z)=\int_{z}^{\eta(t)} S\left(t, z^{\prime}\right) \rho\left(t, z^{\prime}\right) g d z^{\prime}
$$

where $\eta$ is the sea surface height, $t$ is the time, $z$ is the ocean depth, $S$ is salinity in units of kilograms of salt per kilograms of seawater, $\rho$ is the seawater density, and $g$ is gravity.

The freshwater and salt mass differences are proportional to their respective contributions to bottom pressure, $\Delta P_{F} \equiv p_{F}\left(t_{m}\right.$, $\left.z_{b}\right)-p_{F}\left(t_{g}, z_{b}\right)$ and $\Delta P_{S} \equiv p_{S}\left(t_{m}, z_{b}\right)-p_{S}\left(t_{g}, z_{b}\right)$, where $z_{b}$ is the depth of the sea floor. These pressure differences are attributed to columns of freshwater and salt of thickness, $h_{M F}=\Delta P_{F} v_{F} / g$ and $h_{M S}=\Delta P_{S} v_{S} / g$, respectively.

Equations (A1) and (A2) are used to diagnose the added deglacial freshwater and salt. The total added mass for every water column is the sum of freshwater and salt contributions, $h_{M}=h_{M F}+h_{M S}$. The values of $h_{M}$ are similar to the prescribed sea level rise of $130 \mathrm{~m}$ in scenario G12 (top panel, Fig. A1), suggesting that steric effects are small in relation.
The amount of added mass on continental shelves is often less than $126 \mathrm{~m}$ because the modern ocean depth is less than $130 \mathrm{~m}$ there.

Values of $h_{M}$ do not coincide with the sea level rise in each column because the resulting sea surface height gradients are not dynamically balanced by the ocean circulation. Such a sea surface pattern would lead to a rapid mass redistribution until reaching balance with the ocean circulation. Therefore, the values of $h_{M}$ are only useful for balancing the mass budget, not detecting regional sea level rise.

The effect of added mass on global-mean ocean thickness is $\overline{h_{M}}=125.0 \mathrm{~m}$ in scenario G12 and ranges up to $125.4 \mathrm{~m}$ in the other scenarios (Table 1). Despite open-ocean values greater than $130 \mathrm{~m}$, the continental shelves strongly decrease the mean, $\overline{h_{M}}$. Much of the difference between $\overline{h_{M}}$ and the $130 \mathrm{~m}$ of sea level rise is a hypsometric effect on sea level, where the LGM oceanic area was about $6 \%$ less than the modern day (e.g., Becker et al. 2009) which leads to a greater sea level rise for a given amount of added mass.

The spatial pattern of added mass is not identical to the added freshwater map due to the deglacial redistribution of salt (top and middle panels, Fig. A1). Over $2 \mathrm{~m}$ of salt are added or removed from specific water columns (bottom panel, Fig. A1). Pore water observations indicate that Antarctic Bottom Water and Intermediate Water were salty relative to North Atlantic Deep Water, suggesting deglacial salt export (e.g., Adkins et al. 2002). For this reason, we see negative $\overline{h_{M S}}$ values in the Weddell Sea and positive values in the Arctic and North Atlantic.

\section{APPENDIX B}

\section{Steric Height Change in 3D Reconstructions}

The thickness of ocean state $i$ was approximated in Eq. (8) and is here expanded into vertical integrals that are used to diagnose the three-dimensional ocean reconstructions,

$$
H_{i}=\frac{1}{g}\left\{\int_{0}^{\Delta P_{S}} v_{S} d p+\int_{0}^{\Delta P_{F}} v_{F} d p+\int_{0}^{P_{g}} v d p\right\},
$$

where the terms in the curly brackets include the thickness of added salt, the added freshwater, and the glacial ocean, respectively. The integral limits are shifted to increase sequentially,

$H_{i}=\frac{1}{g}\left\{\int_{0}^{\Delta P_{S}} v_{S} d p+\int_{\Delta P_{S}}^{\Delta P} v_{F}\left(p-\Delta P_{S}\right) d p+\int_{\Delta P}^{P_{m}} v\left(t_{g}, p-\Delta P\right) d p\right\}$,

using the relations, $\Delta P=\Delta P_{F}+\Delta P_{S}$ and $P_{g}=P_{m}-\Delta P$. The modern height in Eq. (9) can also be expanded into three terms:

$$
H_{m}=\frac{1}{g}\left\{\int_{0}^{\left|\Delta P_{S}\right|} v\left(t_{m}, p\right) d p+\int_{\left|\Delta P_{S}\right|}^{\Delta P} v\left(t_{m}, p\right) d p+\int_{\Delta P}^{P_{b}} v\left(t_{m}, p\right) d p\right\},
$$


(a)

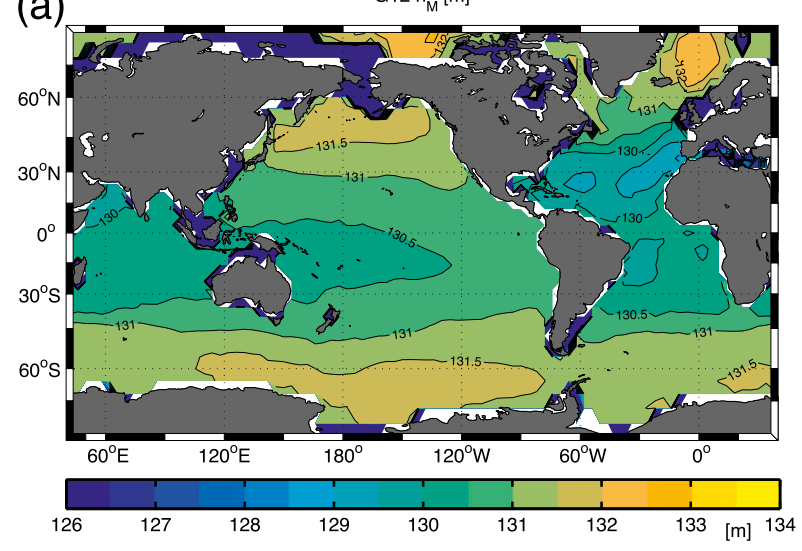

(b)

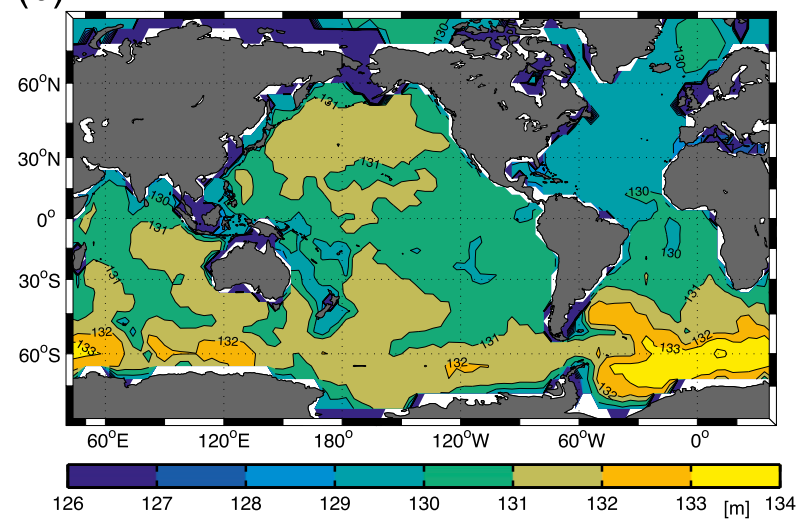

(c)

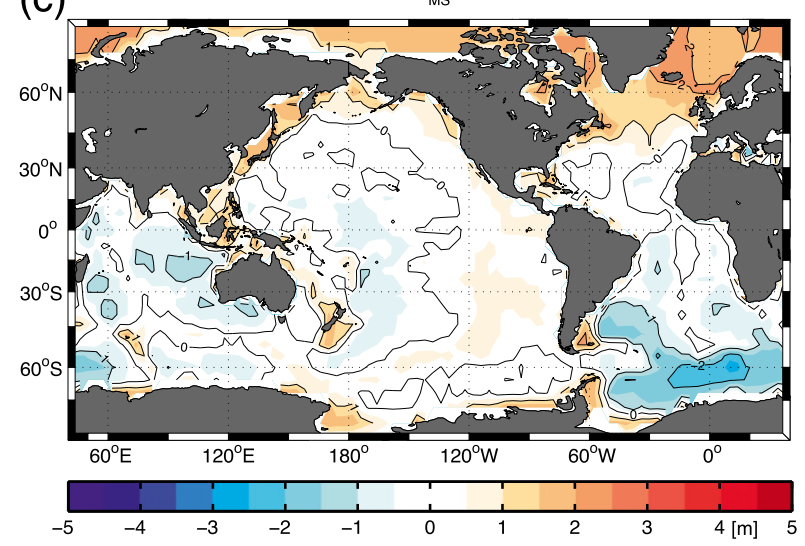

FIG. A1. (a) The combined thickness of freshwater and salt $h_{M}$ needed to balance the deglacial mass budget on a columnby-column basis. The mass balance is accomplished by adding (b) freshwater of thickness $h_{M F}$ and (c) salt of thickness $h_{M S}$. Values on the continental shelves are often much less than $126 \mathrm{~m}$ and are off-scale.

where we use the absolute value (i.e., $\left|\Delta P_{S}\right|$ ) to ensure that pressures are positive.

The steric height change is the difference of (B2) and (B3),

$$
\begin{aligned}
h_{\rho}= & \frac{1}{g}\left\{\int_{0}^{\Delta P_{S}}\left[v\left(t_{m}, p\right)-v_{S}\right] d p+\int_{\Delta P_{S}}^{\Delta P}\left[v\left(t_{m}, p\right)-v_{F}\left(p-\Delta P_{S}\right)\right] d p\right. \\
& \left.+\int_{\Delta P}^{P_{m}}\left[v\left(t_{m}, p\right)-v\left(t_{g}, p-\Delta P\right)\right] d p\right\},
\end{aligned}
$$

which holds for the case of $\Delta P_{S} \geq 0$. In the case that $\Delta P_{S}<0$, Eq. (B4) is rearranged to become

$$
\begin{aligned}
h_{\rho}= & \frac{1}{g}\left\{\int_{\Delta P_{S}}^{0}\left[v_{S}-v\left(t_{g}, p-\Delta P_{S}\right)\right] d p+\int_{0}^{\Delta P}\left[v\left(t_{m}, p\right)\right.\right. \\
& \left.\left.-v_{F}\left(p-\Delta P_{S}\right)\right] d p+\int_{\Delta P}^{P_{m}}\left[v\left(t_{m}, p\right)-v\left(t_{g}, p-\Delta P\right)\right] d p\right\},
\end{aligned}
$$

where the integral limits are returned to sequential order. If $\Delta v$ is defined as

$$
\Delta v= \begin{cases}v_{S}-v\left(t_{g}, p\right) & : \Delta P_{S}<p<0 \\ v\left(t_{m}, p\right)-v_{S} & : 0<p<\Delta P_{S} \\ v\left(t_{m}, p\right)-v_{F}\left(p-\Delta P_{S}\right) & : \max \left(0, \Delta P_{S}\right)<p<\Delta P \\ v\left(t_{m}, p\right)-v\left(t_{g}, p-\Delta P\right) & : \Delta P<p<P_{m}\end{cases}
$$

then the Eqs. (B4) and (B5) are simplified to

$$
h_{\rho}=\frac{1}{g} \int_{P_{0}}^{P_{m}} \Delta v d p,
$$

where $P_{0}=\min \left(0, \Delta P_{S}\right)$. Our decomposition of the steric height change is not unique because the ordering of the freshwater and salt layers could be reversed. Reversal of the layers causes only slight numerical differences because the salt layer imposes pressure shifts of 5 dbar or less.

\section{Diagnostics for steric contributions}

The specific volume change is decomposed into salinity $\Delta v_{s}$, temperature $\Delta v_{\theta}$, pressure $\Delta v_{p}$, and phase-change $\Delta v_{\phi}$ contributions,

$$
\Delta v=\Delta v_{s}+\Delta v_{\theta}+\Delta v_{p}+\Delta v_{\phi}+\Delta v_{\varepsilon}
$$

where $\Delta v_{\varepsilon}$ is the residual. The salinity effect on seawater density $\Delta v_{s}$ always refers to a difference, as opposed to the specific volume of sea salt $v_{S}$, which does not. For example, the temperature effect on seawater specific volume is here defined as

$$
\Delta v_{\theta}=v\left[S^{*}, \Theta\left(t_{m}\right), p^{*}\right]-v\left(S^{*}, \Theta_{i}, p^{*}\right),
$$

where $\Theta_{i}$ is the temperature profile for the intermediate state, and $S^{*}$ and $p^{*}$ are the salinity and pressure of a baseline state. There are multiple ways to define the baseline state, and here we choose to take the average of the diagnostic performed with the glacial and modern states, 


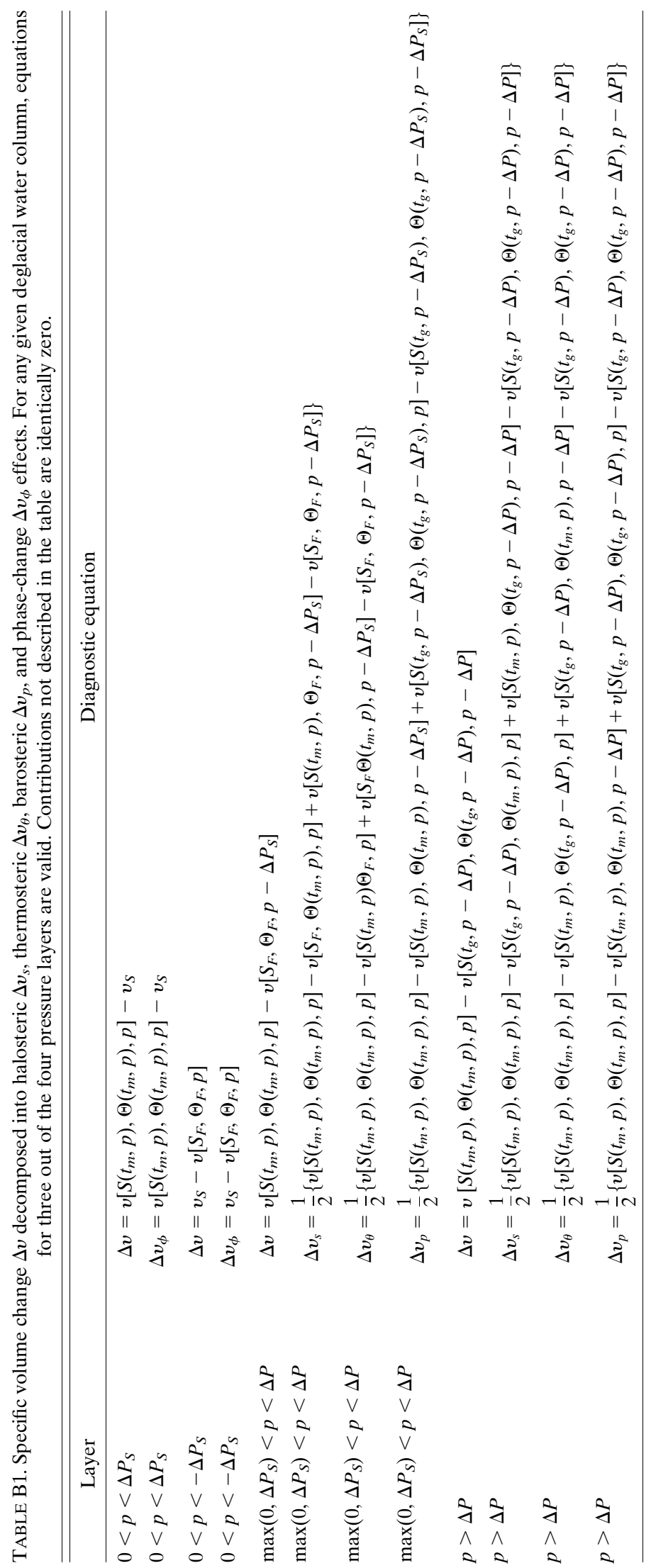




$$
\begin{aligned}
\Delta v_{\theta}= & \frac{1}{2}\left\{v\left[S\left(t_{m}\right), \Theta\left(t_{m}\right), p\left(t_{m}\right)\right]-v\left[S\left(t_{m}\right), \Theta_{i}, p\left(t_{m}\right)\right]\right. \\
& \left.+v\left[S_{i}, \Theta\left(t_{m}\right), p_{i}\right]-v\left[S_{i}, \Theta_{i}, p_{i}\right]\right\},
\end{aligned}
$$

where $S_{i}$ and $p_{i}$ are the intermediate salinity and pressure profiles defined for the pressure range, $p>\max \left(0, \Delta P_{S}\right)$. Equations for the barosteric and halosteric effects are similarly derived (Table B1).

Deglacial specific volume change is well described by temperature, salinity, pressure, and phase-change contributions when diagnosed according to Eq. (B10). The residual in Eq. (B8), $\Delta v_{\varepsilon}$, has a mean and standard deviation of $-7 \times 10^{-5} \mathrm{~kg}^{-1} \mathrm{~m}^{3}$ and $6 \times 10^{-5} \mathrm{~kg}^{-1} \mathrm{~m}^{3}$, respectively. The thickness change of a water column is related to the specific volume change by

$$
\begin{aligned}
& h_{\rho s}=\int_{P_{0}}^{P_{m}} \frac{\Delta v_{s}}{g} d p, \quad h_{\rho \theta}=\int_{P_{0}}^{P_{m}} \frac{\Delta v_{\theta}}{g} d p, \quad h_{\rho p}=\int_{P_{0}}^{P_{m} \Delta v_{p}} \frac{1}{g} d p, \\
& h_{\rho \phi}=\int_{P_{0}}^{P_{m} \Delta v_{\phi}} \frac{}{g} d p,
\end{aligned}
$$

where the following relation, $h_{\rho}=h_{\rho s}+h_{\rho \theta}+h_{\rho p}+h_{\rho \phi}$, holds with a standard error of $2 \mathrm{~mm}$.

\section{APPENDIX C}

\section{Sample Water Column Calculations}

The complete calculations for the temperature, salinity, pressure, and phase-change effects on seawater density are presented for a water column at $26^{\circ} \mathrm{W}, 20^{\circ} \mathrm{S}$ in the Brazil Basin. The LGM-to-modern pressure difference at the sea floor is $\Delta P=125.8$ dbar. Here we compare the modern salinity for pressures, $p>125.8 \mathrm{dbar}$, to the LGM salinity at pressure, $p-$ $\Delta P$ (top-left panel, Fig. C1). As expected, the glacial ocean is everywhere saltier than the modern, due to the freshwater locked up in land ice. The vertical structure of salinity is different during glacial times, as the middepth northern sourced water is fresher than the southern-source waters above and below. The abyssal South Atlantic started from saltier conditions, and there is more freshening over the deglaciation at those depths (Adkins et al. 2002). At the surface, glacial salinity approaches $40 \mathrm{~g} \mathrm{~kg}^{-1}$, and is indirectly informed by the surface $\delta^{18} \mathrm{O}$ necessary to fit benthic foraminiferal records.

The reconstructed LGM temperature is everywhere $2^{\circ}-5^{\circ} \mathrm{C}$ cooler than the modern, even with the suggested pressure offset (top-right panel, Fig. C1). Below about $1200 \mathrm{~m}$ depth, the LGM temperature is homogeneous with temperatures below $0^{\circ} \mathrm{C}$. We infer that North Atlantic Deep Water is the deep water mass that warmed most.

Equations (B6) and (B10) are used to diagnose LGM-tomodern specific volume changes (also see Table B1). The specific volume change is positive for $p>\Delta P$ (bottom-left panel, Fig. C1), indicative of expansion due to warming and freshening. The halosteric effect reflects greater expansion at the sea floor and near $p=\Delta P$. The expansion by freshening is compensated by the contraction of freshwater in the upper ocean. Thermal expansion is also a function of depth,
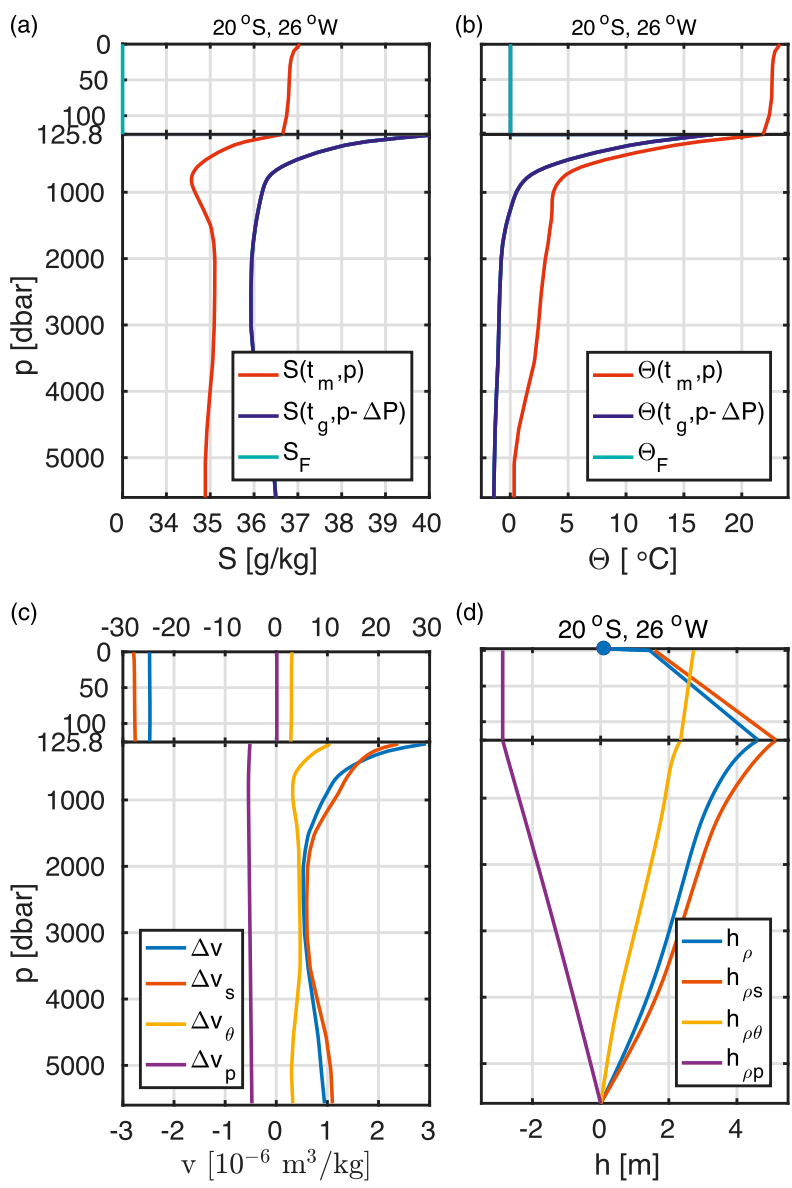

FIG. C1. (a) Profiles of Absolute Salinity at $25^{\circ} \mathrm{S}, 20^{\circ} \mathrm{W}$, for the modern $\left[S\left(t_{m}, p\right)\right.$, red], the G12 LGM scenario with a pressure offset $\left[S\left(t_{g}, p-\Delta P\right)\right.$, blue], and freshwater $\left(S_{F}=0 \mathrm{~g} \mathrm{~kg}^{-1}\right.$, cyan $)$. Note the expanded pressure axis for $p<\Delta P$ and the break in the salinity scale to accommodate off-scale fresh waters. (b) As in (a), but for Conservative Temperature $\Theta$. (c) Specific volume change $(\Delta v$, blue $)$ and its decomposition into salinity $\left(\Delta v_{S}\right.$, orange), temperature $\left(\Delta v_{T}\right.$, yellow $)$, and pressure $\left(\Delta v_{P}\right.$, purple) contributions. For $p<\Delta P$, both $x$ and $y$ axes are expanded. (d) Height change of isobaric surfaces due to steric effects $\left(\eta_{\rho}\right.$, blue) and its decomposition into halosteric $\left(\eta_{\rho s}\right.$, orange), thermosteric $\left(\eta_{\rho \theta}\right.$, yellow), and barosteric ( $\eta_{\rho p}$, purple) contributions. The phase-change contribution is denoted at the sea surface $\left(\eta_{\rho \phi}\right.$, blue circle).

where this expansion is reduced in the upper ocean due to the properties of cold and freshwater (e.g., McDougall and Feistel 2003).

The specific volume anomalies are integrated from the sea floor to the surface to give the steric impact on sea level rise or fall (lower-right panel, Fig. C1). More specifically, we integrate the difference in the isobaric height between the intermediate and modern oceans to determine the effect of ocean density changes,

$$
\eta_{\rho}(p)=\int_{p}^{P_{m}} \frac{\Delta v\left(p^{\prime}\right)}{g} d p^{\prime},
$$


where $\eta_{\rho}(p)$ is the change in depth of the isobaric surface at pressure $p$. By definition, the height change at atmospheric pressure is equal to the change in thickness of the water column, $h_{\rho} \equiv \eta_{\rho}(0)$. Similarly we define quantities for the thermosteric, barosteric, halosteric, and phase-change effects.

The interior ocean expands by $\eta_{\rho}(\Delta P)=4.6 \mathrm{~m}$, and the meltwater lid contracts by $3.2 \mathrm{~m}$. There is a cumulative halosteric effect of $h_{\rho s}=\eta_{s}(0)=1.6 \mathrm{~m}$ because of a net export of salt that exceeds the global dilution effect from melting land ice. The cumulative thermosteric effect of $h_{\rho \theta}=\eta_{\theta}(0)=$ $2.7 \mathrm{~m}$ is completely compensated by the barosteric effect of $h_{\rho p}=-2.9 \mathrm{~m}$. The phase-change effect, $h_{\rho \phi}=-1.4 \mathrm{~m}$, occurs in the upper $2 \mathrm{~m}$ and is captured by the total steric effect being adjusted downward at the surface (blue dot, lower-right panel, Fig. C1). The net effect is a near compensation of all contributions leading to only a slight $(<0.1 \mathrm{~m})$ expansion.

\section{REFERENCES}

Adkins, J. F., K. McIntyre, and D. P. Schrag, 2002: The salinity, temperature, and $\delta^{18} \mathrm{O}$ of the glacial deep ocean. Science, 298, 1769-1773, https://doi.org/10.1126/science.1076252

Amrhein, D. E., C. Wunsch, O. Marchal, and G. Forget, 2018: A global glacial ocean state estimate constrained by upper-ocean temperature proxies. J. Climate, 31, 8059-8079, https://doi.org/ 10.1175/JCLI-D-17-0769.1

Austermann, J., J. X. Mitrovica, K. Latychev, and G. A. Milne, 2013: Barbados-based estimate of ice volume at Last Glacial Maximum affected by subducted plate. Nat. Geosci., 6, 553557, https://doi.org/10.1038/ngeo1859

Bassett, S., G. Milne, M. Bentley, and P. Huybrechts, 2007: Modelling Antarctic sea-level data to explore the possibility of a dominant Antarctic contribution to meltwater pulse 1A. Quat. Sci. Rev., 26, 2113-2127, https://doi.org/10.1016/ j.quascirev.2007.06.011

Becker, J., and Coauthors, 2009: Global bathymetry and elevation data at 30 arc seconds resolution: SRTM30_PLUS. Mar. Geod., 32, 355-371, https://doi.org/10.1080/01490410903297766

Bereiter, B., K. Kawamura, and J. P. Severinghaus, 2018a: New methods for measuring atmospheric heavy noble gas isotope and elemental ratios in ice core samples. Rapid Commun. Mass Spectrom., 32, 801-814, https://doi.org/10.1002/rcm.8099

- S. Shackleton, D. Baggenstos, K. Kawamura, and J. Severinghaus, 2018b: Mean global ocean temperatures during the last glacial transition. Nature, 553, 39-44, https://doi.org/10.1038/ nature 25152

Berger, A., Q. Yin, H. Nifenecker, and J. Poitou, 2017: Slowdown of global surface air temperature increase and acceleration of ice melting. Earth's Future, 5, 811-822, https://doi.org/10.1002/ 2017EF000554

Bindoff, N. L., and Coauthors, 2007: Observations: Oceanic climate and sea level. Climate Change 2007: The Physical Science Basis, S. Solomon et al., Eds. Cambridge University Press, 385-432.

Breitkreuz, C., A. Paul, and M. Schulz, 2019: A dynamical reconstruction of the last glacial maximum ocean state constrained by global oxygen isotope data. Climate Past Discuss., https:// doi.org/10.5194/cp-2019-52.

Carlson, A. E., L. Tarasov, and T. Pico, 2018: Rapid Laurentide icesheet advance towards southern Last Glacial Maximum limit during marine isotope stage 3. Quat. Sci. Rev., 196, 118-123, https://doi.org/10.1016/j.quascirev.2018.07.039
Clark, P. U., and L. Tarasov, 2014: Closing the sea level budget at the last glacial maximum. Proc. Natl. Acad. Sci. USA, 111, 15 861-15 862, https://doi.org/10.1073/pnas.1418970111

Galbraith, E. D., T. M. Merlis, and J. B. Palter, 2016: Destabilization of glacial climate by the radiative impact of Atlantic Meridional Overturning Circulation disruptions. Geophys. Res. Lett., 43, 8214-8221, https://doi.org/10.1002/ 2016GL069846

Gebbie, G., 2012: Tracer transport timescales and the observed Atlantic-Pacific lag in the timing of the last Termination. Paleoceanography, 27, PA3225, https://doi.org/10.1029/ 2011PA002273

_ 2014: How much did Glacial North Atlantic Water shoal? Paleoceanography, 29, 190-209, https://doi.org/10.1002/ 2013PA002557

—- C. D. Peterson, L. E. Lisiecki, and H. J. Spero, 2015: Global-mean $\delta^{13} \mathrm{C}$ and its uncertainty in a glacial state estimate. Quat. Sci. Rev., 125, 144-159, https://doi.org/10.1016/ j.quascirev.2015.08.010.

—, A. R. Simms, and L. E. Lisiecki, 2019: Why estimates of deglacial ice loss should be biased low. Earth Planet. Sci. Lett., 515, 112-124, https://doi.org/10.1016/j.epsl.2019.03.017

Gille, S. T., 2004: How nonlinearities in the equation of state of seawater can confound estimates of steric sea level change. J. Geophys. Res., 109, C03005, https://doi.org/10.1029/ 2003JC002012

Gomez, N., J. X. Mitrovica, M. E. Tamisiea, and P. U. Clark, 2010: A new projection of sea level change in response to collapse of marine sectors of the Antarctic Ice Sheet. Geophys. J. Int., 180, 623-634, https://doi.org/10.1111/j.1365-246X.2009.04419.x

Gouretski, V., and K. Koltermann, 2004: WOCE Global Hydrographic Climatology. Tech. Rep. 35, Berichte des Bundesamtes für Seeschifffahrt und Hydrographie, 52 pp.

Gregory, J. M., and Coauthors, 2013: Twentieth-century globalmean sea level rise: Is the whole greater than the sum of the parts? J. Climate, 26, 4476-4499, https://doi.org/10.1175/JCLID-12-00319.1

— , and Coauthors, 2019: Concepts and terminology for sea level: Mean, variability and change, both local and global. Surv. Geophys., 40, 1251-1289, https://doi.org/10.1007/s10712-019-09525-z

Griffies, S. M., and R. J. Greatbatch, 2012: Physical processes that impact the evolution of global mean sea level in ocean climate models. Ocean Modell., 51, 37-72, https://doi.org/10.1016/ j.ocemod.2012.04.003

Hesse, T., M. Butzin, T. Bickert, and G. Lohmann, 2011: A modeldata comparison of $\delta^{13} \mathrm{C}$ in the glacial Atlantic Ocean. Paleoceanography, 26, PA3220, https://doi.org/10.1029/ 2010PA002085.

IOC, SCOR, and IAPSO, 2010: The International Thermodynamic Equation of Seawater-2010: Calculation and use of thermodynamic properties. Intergovernmental Oceanographic Commission, Manuals and Guides 56, UNESCO, 196 pp., http:// www.teos-10.org/pubs/TEOS-10_Manual.pdf.

Kucera, M., A. Rosell-Mele, R. Schneider, C. Waelbroeck, and M. Weinelte, 2006: Multiproxy Approach for the Reconstruction of the Glacial Ocean surface (MARGO). Quat. Sci. Rev., 24, 813-1107.

Kuhlbrodt, T., and J. Gregory, 2012: Ocean heat uptake and its consequences for the magnitude of sea level rise and climate change. Geophys. Res. Lett., 39, L18608, https://doi.org/10.1029/ 2012GL052952

Kurahashi-Nakamura, T., A. Paul, and M. Losch, 2017: Dynamical reconstruction of the global ocean state during the last glacial 
maximum. Paleoceanography, 32, 326-350, https://doi.org/ 10.1002/2016PA003001

Lambeck, K., and J. Chappell, 2001: Sea level change through the last glacial cycle. Science, 292, 679-686, https://doi.org/10.1126/ science.1059549

- , H. Rouby, A. Purcell, Y. Sun, and M. Sambridge, 2014: Sea level and global ice volumes from the Last Glacial Maximum to the Holocene. Proc. Natl. Acad. Sci. USA, 111, 1529615303, https://doi.org/10.1073/pnas.1411762111

Levermann, A., P. U. Clark, B. Marzeion, G. A. Milne, D. Pollard, V. Radic, and A. Robinson, 2013: The multimillennial sealevel commitment of global warming. Proc. Natl. Acad. Sci. USA, 110, 13 745-13 750, https://doi.org/10.1073/pnas.1219414110

Levitus, S., and Coauthors, 2012: World ocean heat content and thermosteric sea level change (0-2000 m), 1955-2010. Geophys. Res. Lett., 39, L10603, https://doi.org/10.1029/ 2012GL051106.

Lowe, J. A., and J. M. Gregory, 2006: Understanding projections of sea level rise in a Hadley Centre coupled climate model. J. Geophys. Res., 111, C11014, https://doi.org/10.1029/2005JC003421

Maris, M., B. De Boer, S. Ligtenberg, M. Crucifix, W. Van De Berg, and J. Oerlemans, 2014: Modelling the evolution of the Antarctic ice sheet since the last interglacial. Cryosphere, $\mathbf{8}$, 1347-1360, https://doi.org/10.5194/tc-8-1347-2014

Martin, J.-M., and M. Whitfield, 1983: The significance of the river input of chemical elements to the ocean. Trace Metals in Sea Water, Springer, 265-296.

McDougall, T. J., and R. Feistel, 2003: What causes the adiabatic lapse rate? Deep-Sea Res. I, 50, 1523-1535, https://doi.org/ 10.1016/j.dsr.2003.09.007

McKay, N. P., J. T. Overpeck, and B. L. Otto-Bliesner, 2011: The role of ocean thermal expansion in Last Interglacial sea level rise. Geophys. Res. Lett., 38, L14605, https://doi.org/10.1029/ 2011GL048280

Meehl, G., and Coauthors, 2007: Global climate projections. Climate Change 2007: The Physical Science Basis, S. Solomon et al., Eds., Cambridge University Press, 747-846.

Mitrovica, J. X., and W. R. Peltier, 1991: On postglacial geoid subsidence over the equatorial oceans. J. Geophys. Res., 96, $20053-20071$, https://doi.org/10.1029/91JB01284

Munk, W., 2003: Ocean freshening, sea level rising. Science, 300, 2041-2043, https://doi.org/10.1126/science.1085534

Nakada, M., J. Okuno, and Y. Yokoyama, 2016: Total meltwater volume since the Last Glacial Maximum and viscosity structure of Earth's mantle inferred from relative sea level changes at Barbados and Bonaparte Gulf and GIA-induced J2. Geophys. J. Int., 204, 1237-1253, https://doi.org/10.1093/gij/ggv520
Patton, H., A. Hubbard, K. Andreassen, M. Winsborrow, and A. P. Stroeven, 2016: The build-up, configuration, and dynamical sensitivity of the Eurasian ice-sheet complex to Late Weichselian climatic and oceanic forcing. Quat. Sci. Rev., 153, 97-121, https://doi.org/10.1016/j.quascirev.2016.10.009

Peterson, C. D., L. E. Lisiecki, and J. V. Stern, 2014: Deglacial whole-ocean $\delta^{13} \mathrm{C}$ change estimated from 480 benthic foraminiferal records. Paleoceanography, 29, 549-563, https:// doi.org/10.1002/2013PA002552

Pico, T., L. Birch, J. Weisenberg, and J. Mitrovica, 2018: Refining the Laurentide Ice Sheet at Marine Isotope Stage 3: A databased approach combining glacial isostatic simulations with a dynamic ice model. Quat. Sci. Rev., 195, 171-179, https:// doi.org/10.1016/j.quascirev.2018.07.023

Piecuch, C., and R. Ponte, 2011: Mechanisms of interannual steric sea level variability. Geophys. Res. Lett., 38, L15605, https:// doi.org/10.1029/2011GL048440

Pilson, M. E. Q., 1998: An Introduction to the Chemistry of the Sea. Prentice Hall, 431 pp.

Rye, C. D., A. C. N. Garabato, P. R. Holland, M. P. Meredith, A. G. Nurser, C. W. Hughes, A. C. Coward, and D. J. Webb, 2014: Rapid sea-level rise along the Antarctic margins in response to increased glacial discharge. Nat. Geosci., 7, 732-735, https:// doi.org/10.1038/ngeo2230

Simms, A. R., L. E. Lisiecki, G. Gebbie, P. Whitehouse, and J. F. Clark, 2019: Balancing the Last Glacial Maximum (LGM) sealevel budget. Quat. Sci. Rev., 205, 143-153, https://doi.org/ 10.1016/j.quascirev.2018.12.018

Skinner, L. C., and N. J. Shackleton, 2005: An Atlantic lead over Pacific deep-water change across Termination I: Implications for the application of the marine isotope stage stratigraphy. Quat. Sci. Rev., 24, 571-580, https://doi.org/10.1016/ j.quascirev.2004.11.008

Stammer, D., A. Cazenave, R. M. Ponte, and M. E. Tamisiea, 2013: Causes for contemporary regional sea level changes. Annu. Rev. Mar. Sci., 5, 21-46, https://doi.org/10.1146/annurev-marine121211-172406

Tada, R., and R. Siever, 1986: Experimental knife-edge pressure solution of halite. Geochim. Cosmochim. Acta, 50, 29-36, https://doi.org/10.1016/0016-7037(86)90045-1

Waelbroeck, C., and Coauthors, 2009: Constraints on the magnitude and patterns of ocean cooling at the Last Glacial Maximum. Nat. Geosci., 2, 127-132, https://doi.org/10.1038/ngeo411

Yokoyama, Y., T. M. Esat, and K. Lambeck, 2001: Coupled climate and sea-level changes deduced from Huon Peninsula coral terraces of the last ice age. Earth Planet. Sci. Lett., 193, 579587, https://doi.org/10.1016/S0012-821X(01)00515-5 